\title{
Preclinical evaluation of cyclin dependent kinase 11 and casein kinase 2 survival kinases as RNA interference targets for triple negative breast cancer therapy
}

Betsy T Kren ${ }^{1,2,3}$, Gretchen M Unger ${ }^{4}$, Md J Abedin ${ }^{1,2}$, Rachel I Vogel ${ }^{3}$, Christine M Henzler ${ }^{2,5}$, Khalil Ahmed ${ }^{1,2,3,6}$ and Janeen $\mathrm{H}_{\text {Trembley }}{ }^{1,2,3^{*}}$

\begin{abstract}
Introduction: Targeted therapies for aggressive breast cancers like triple negative breast cancer (TNBC) are needed. The use of small interfering RNAs (siRNAs) to disable expression of survival genes provides a tool for killing these cancer cells. Cyclin dependent kinase 11 (CDK11) is a survival protein kinase that regulates RNA transcription, splicing and mitosis. Casein kinase 2 (CK2) is a survival protein kinase that suppresses cancer cell death. Eliminating the expression of these genes has potential therapeutic utility for breast cancer.

Methods: Expression levels of CDK11 and CK2 mRNAs and associated proteins were examined in breast cancer cell lines and tissue arrays. RNA expression levels of CDC2L1, CDC2L2, CCNL1, CCNL2, CSNK2A1, CSNK2A2, and CSNK2B genes in breast cancer subtypes were analyzed. Effects following transfection of siRNAs against CDK11 and CK2 in cultured cells were examined by viability and clonal survival assays and by RNA and protein measures. Uptake of tenfibgen (TBG) nanocapsules by TNBC cells was analyzed by fluorescence-activated cell sorting. TBG nanocapsules delivered siRNAs targeting CDK11 or CK2 in mice carrying TNBC xenograft tumors. Transcript cleavage and response parameters were evaluated.

Results: We found strong CDK11 and CK2 mRNA and protein expression in most human breast cancer cells. Immunohistochemical analysis of TNBC patient tissues showed 100\% of tumors stained positive for CDK11 with high nuclear intensity compared to normal tissue. The Cancer Genome Atlas analysis comparing basal to other breast cancer subtypes and to normal breast revealed statistically significant differences. Down-regulation of CDK11 and/or CK2 in breast cancer cells caused significant loss of cell viability and clonal survival, reduced relevant mRNA and protein expression, and induced cell death changes. TBG nanocapsules were taken up by TNBC cells both in culture and in xenograft tumors. Treatment with TBG- siRNA to CDK11 or TBG- siRNA to CK2aa' nanocapsules induced appropriate cleavage of CDK11 and CK2a transcripts in TNBC tumors, and caused MDA-MB-231 tumor reduction, loss of proliferation, and decreased expression of targeted genes.
\end{abstract}

Conclusions: CDK11 and CK2 expression are individually essential for breast cancer cell survival, including TNBC. These genes serve as promising new targets for therapeutic development in breast cancer.

\footnotetext{
* Correspondence: trem0005@umn.edu

${ }^{1}$ Research Service (151), Minneapolis VA Health Care System, One Veterans

Drive, Minneapolis, MN 55417, USA

${ }^{2}$ Department of Laboratory Medicine and Pathology, University of Minnesota,

420 Delaware Street, SE, Minneapolis, MN, USA

Full list of author information is available at the end of the article
} 


\section{Introduction}

Targeted therapies for hormone receptor expression positive and for human epidermal growth factor receptor 2 (HER2, also known as ERBB2 or EGFR2) overexpression-positive disease have improved breast cancer mortality; however, breast cancer lacking these receptors, termed triple negative breast cancer (TNBC), presents particular challenges because of its highly aggressive nature. Given the need for new approaches to treat $\mathrm{TNBC}$, we investigated the effectiveness of downregulation of the essential protein kinases cyclindependent kinase (CDK) 11 and casein kinase 2 (CK2) using RNA interference (RNAi) for killing this aggressive form of breast cancer. When targeting a survival gene, an RNAi or small interfering RNA (siRNA) approach to downregulate or eliminate the survival protein expression, and thus its function, has advantages of great flexibility and specificity in choosing the target. The difficulty in such an approach when moving to systemic organismal use comes with delivery of the nucleic acids in a protected and tumor-directed manner. We have developed tenfibgen (TBG) nanoencapsulation technology that allows for delivery of nucleic acids into malignant cells in vivo while avoiding accumulation in normal cells [1-3].

The first CDK family members characterized were the catalytic subunits that formed heterodimers with regulatory partner proteins, called cyclins. The prototypical CDKs (such as CDK1 and CDK2) displayed cell cycle phase-specific activity; however, there are now members of the CDK family that play more varied roles in cellular regulation [4,5]. CDK11 (formerly named PITSLRE) is a somewhat atypical CDK that is essential for cell survival [6,7]. CDK11 is evolutionarily well conserved with two almost identical CDK11 genes in humans $(C D C 2 L 1$ and $C D C 2 L 2$ ) and one CDK11 gene in other organisms, including mice [8]. Cyclin L1 (CCNL1) and cyclin L2 (CCNL2) are confirmed regulatory partner proteins for CDK11 [9-14]. Expression of both CDK11 and cyclin L1 is increased in various cancers, with amplification of CCNL1 associated with poor prognosis [15-20]. Transcription and alternative splicing generate more than 20 distinct CDK11 mRNA and protein isoforms in human cells, and the alternative splicing involves exons encoding the $\mathrm{N}$-terminal domain, but not exons in the Cterminal kinase catalytic domain [8]. Gene mutation does not play a significant role in CDK11 function in cancer, and the majority of mutations reported are missense, suggesting again the essential nature of CDK11 function (Sanger COSMIC database).

The predominant CDK11 protein isoforms during cell proliferation are designated p110 and p58 for their respective observed mass by polyacrylamide gel electrophoresis $\left(\mathrm{CDK} 11^{\mathrm{p} 110}, \mathrm{CDK} 11^{\mathrm{p} 58}\right)$. The $\mathrm{CDK} 11^{\mathrm{p} 110}$ protein isoforms are ubiquitously expressed in mammalian tissues and cell lines during proliferation and throughout the cell cycle [21]; moreover, CDK11 ${ }^{\text {p110 }}$ continues to be detected by immunoblot in quiescent mouse liver [9]. The p110 isoforms associate with multiple transcription and splicing related proteins via the N-terminal (nonkinase) domain and have been shown to influence transcription and splicing activities [9,22-28]. The CDK11 ${ }^{\mathrm{p} 58}$ isoforms are translated at the G2/M cell cycle transition from an internal ribosomal entry site on the same mRNA transcripts that produce the p110 isoforms [29]. CDK11 ${ }^{\mathrm{p} 58}$ is only produced during a very narrow window, and is therefore difficult to detect in unsynchronized cells. CDK $11^{\mathrm{p} 58}$ is necessary for successful mitosis and is involved with centrosome maturation, bipolar spindle formation, and centriole duplication [6,30-35].

The CK2 (formerly casein kinase II) enzyme is a wellestablished cancer target with a heterotetrameric composition of two catalytic $\alpha$ and/or $\alpha$ subunits (42 and $38 \mathrm{kDa}$, respectively) joined together by two $\beta$ subunits $(28 \mathrm{kDa})$. CK2 phosphorylates a vast number of substrates, thereby influencing a multitude of cellular processes [36]. CK2 does not require specific activation, and thus generally exhibits constitutive activity in cells with minor fluctuations in expression or activity from various signaling inputs [37-40]. CK2 is ubiquitous, its steadystate levels are distinct for various cell types, and its expression in different tissues under normal conditions remains constant. However, increased CK2 protein expression and activity is observed in a broad range of cancers including breast cancer, correlates with increased nuclear localization, is not associated with any mutational changes in CK2 genes, and serves as a prognostic indicator [41-49]. Notably, expression of CK2 $\alpha$ in the mouse mammary gland under control of the mouse mammary tumor virus long terminal repeat (MMTVLTR) gave rise to a transgenic mouse model of breast cancer [50]. Finally, suppression of apoptosis by CK2 supports its role in cell survival, thus decisively connecting CK2 upregulation and function to the cancer cell phenotype [42,51].

Owing to the essential roles for CDK11 and CK2 in both cycling and noncycling cells, tumor-targeted delivery of a therapeutic is important. To accomplish protected tumor cell-specific in vivo delivery of siRNAs, the nucleic acid is condensed and coated with a TBG protein shell that is recognized by tenascin- $\mathrm{C}$ receptors $[2,52,53]$. Tenascin-C-rich stroma has been observed consistently adjacent to the epithelial cell nests of breast [54] and other cancers; further, tenascin-C appears to play a role in initiating and sustaining lung colonization of breast cancer cells [55]. TBG nanocapsule cellular uptake utilizes a lipid raft-mediated caveolar pathway 
$[1,56]$. The TBG-based nanocapsules containing siRNA average 10 to $30 \mathrm{~nm}$ in size, display a slight negative charge, and exist as uniform nonaggregated particles in solution. The TBG-siCK2 nanocapsule has been shown to be specific for malignant and not normal prostate cells in culture, and a similar TBG-RNAi-CK2 nanocapsule has been shown to be specific for malignant and not normal tissues in mice [1-3].

Our data presented herein demonstrate that both CDK11 and CK2 kinases are well expressed in breast cancer cells and are essential for cell survival. TBG nanocapsules enter human TNBC cells, both in cell culture and when systemically administered to mice carrying xenograft tumors. TBG-siCDK11-treated or TBG-siCK2-treated MDA-MB-231 tumors showed reduced target protein expression and response parameters that included decreased proliferation, tumor mass, and tumor volume relative to controls.

\section{Materials and methods}

Cell lines and culture

MCF-10A, MCF-12A, MDA-MB-468, and BT-474 cells were obtained from ATCC (Manassas, VA, USA). MDAMB-231 and MCF-7 cells were a gift from Dr David Potter (University of Minnesota, MN, Minneapolis, USA). Tamoxifen-resistant MCF-7 L (MCF-7L ${ }^{\text {TamR }}$ ) cells were a gift from Dr Douglas Yee (University of Minnesota). SUM-149 and SUM-190 cells were a gift from Dr Sofia Merajver (University of Michigan, MI, Ann Arbor, USA). Growth conditions include: MDA-MB-231 in Dulbecco's modified Eagle's medium (DMEM)/F12 (SH30023; HyClone Logan, Utah, USA), 10\% fetal bovine serum (FBS), 1\% penicillin-streptomycin; MCF-7 in phenol-free DMEM/F12 (SH30272; Hyclone), 10\% charcoal-stripped FBS, $10 \mu \mathrm{g} / \mathrm{ml}$ bovine insulin, $1 \%$ penicillin-streptomycin; MCF-10A in DMEM/F12, 5\% horse serum, $20 \mathrm{ng} / \mathrm{ml}$ human epidermal growth factor, $100 \mathrm{ng} / \mathrm{ml}$ cholera toxin, $10 \mu \mathrm{g} / \mathrm{ml}$ bovine insulin, $500 \mathrm{ng} / \mathrm{ml}$ hydrocortisone; MCF-12A in DMEM/F12, $5 \%$ horse serum, $20 \mathrm{ng} / \mathrm{ml}$ human epidermal growth factor, $100 \mathrm{ng} / \mathrm{ml}$ cholera toxin, $10 \mu \mathrm{g} / \mathrm{ml}$ bovine insulin, $500 \mathrm{ng} / \mathrm{ml}$ hydrocortisone; MDA-MB-468 in DMEM (11995; Gibco Carlsbad, CA, USA), 10\% FBS, 1\% penicillin-streptomycin; MCF-7 L/Tam ${ }^{\mathrm{R}}$ in phenol-free DMEM/F12, 5\% charcoalstripped FBS, $5 \mu \mathrm{g} / \mathrm{ml}$ bovine insulin, $1 \%$ penicillin-streptomycin; SUM-149 in Ham's F12 (11765; Gibco), 5\% FBS, $5 \mu \mathrm{g} / \mathrm{ml}$ bovine insulin, $1 \mu \mathrm{g} / \mathrm{ml}$ hydrocortisone, $0.5 \mu \mathrm{g} / \mathrm{ml}$ amphotericin B, $5 \mu \mathrm{g} / \mathrm{ml}$ gentamycin; and SUM-190 in Ham's F12, $0.5 \mathrm{~g} / \mathrm{l}$ bovine serum albumin, $5 \mathrm{mM}$ ethanolamine, $10 \mathrm{mM}$ HEPES, $5 \mu \mathrm{g} / \mathrm{ml}$ transferrin, $10 \mathrm{nM} \mathrm{3,3',5-}$ triiodo-L-thyronine, $50 \mathrm{nM}$ sodium selenite, $5 \mu \mathrm{g} / \mathrm{ml}$ bovine insulin, $1 \mu \mathrm{g} / \mathrm{ml}$ hydrocortisone, $0.5 \mu \mathrm{g} / \mathrm{ml}$ amphotericin $\mathrm{B}$, $5 \mu \mathrm{g} / \mathrm{ml}$ gentamycin. Cells were grown in an incubator at $37^{\circ} \mathrm{C}$ with $5 \%$ carbon dioxide, with the exception of the SUM cell lines that were grown with $10 \%$ carbon dioxide.
All cells had undetectable levels of mycoplasma when thawed, and were maintained in culture for up to 3 months. The MDA-MB-231, SUM-149, SUM-190, MCF-7, and MCF-7L ${ }^{\text {TamR }}$ cell lines were authenticated by STR profiling (IDEXX BioResearch, Columbia, MO, USA).

\section{Oligonucleotides}

Standard chemistry siRNAs were obtained from Dharmacon (Lafayette, CO, USA). The sense strand sequences are: siCK2, 5' -auacaacccaaacuccacauuudTdT-3' [2]; siCDK11, 5'-gagcgagcagcagcgugugdTdT-3' [30]; and siCON1, 5'uagcgacuaaacacaucaauudTdT-3' [57].

\section{Immunofluorescence and immunohistochemical analyses}

Ki-67 staining was performed by the Pathology and Laboratory Medicine Service (Minneapolis VA Health Care System, Minneapolis, MN, USA). Analysis of the Ki-67 staining was performed using the ImmunoRatio web application [58].

CDK11 staining was tested by immunofluorescence analysis in cultured cells and by immunohistochemical analysis in xenograft tumor tissues using anti-CDK11 rabbit polyclonal antibodies from Santa Cruz Biotechnology (PITSLRE sc-928; Santa Cruz, CA, USA) and from Bethyl Laboratories (A300-311A; Montgomery, TX, USA). A negative control section (without primary antibody) was included in the testing to verify the specificity of the signal. The Bethyl Laboratories antibody was chosen for immunofluorescence work and the Santa Cruz antibody was chosen for immunohistochemical work.

For immunofluorescence analyses, breast cancer cells were plated onto glass coverslips precoated with either poly-D-lysine at $0.5 \mathrm{mg} / \mathrm{ml}$ (P6407; Sigma St. Louis, MO, USA) or with Matrigel at $0.33 \mathrm{mg} / \mathrm{ml}$ (354234; BD Biosciences San Jose, CA, USA). Next day, the cells were fixed in 2\% paraformaldehyde for 15 minutes at room temperature, washed three times in phosphate-buffered saline (PBS), incubated for 30 minutes in glycine (100 mM, pH 7.4), and washed three times in PBS. The fixed cells were permeabilized with $0.1 \%$ Triton X-100/ PBS for 3 minutes, and then washed three times in PBS. Cells were incubated with Sea Block containing $6 \mathrm{mg} / \mathrm{ml}$ normal donkey for 30 minutes at room temperature, washed once in PBS, then incubated with CDK11 antibody (A300-311A, $2 \mu \mathrm{g} / \mathrm{ml}$; Bethyl Laboratories) in a humidified container at $37^{\circ} \mathrm{C}$ for 1 hour. Cells were washed three times for 5 minutes in PBS containing 0.05\% Igepal CA-630 (Sigma) and incubated with secondary antibody (donkey anti-rabbit F(ab')2 DyLight-488 711-486$152,0.75 \mathrm{mg} / \mathrm{ml}$ in $50 \%$ glycerol, 1:400; Jackson Immunoresearch, West Grove, PA, USA) in a humidified container at $37^{\circ} \mathrm{C}$ for 1 hour. Cells were washed six times for 5 minutes in PBS containing 0.05\% Igepal CA-630 and counterstained using Slowfade Gold containing 
DAPI (S36938; Invitrogen Carlsbad, CA, USA). Images were captured using an Olympus BX60 (Shinjuku, Toyko, Japan) fluorescent microscope at $40 \times$ objective with a digital color Q Imaging Retiga 2000R Fast1394 camera (Surrey, British Columbia, Canada).

CDK11 immunohistochemical staining was performed on the following commercially purchased arrays (US Biomax, Inc. Rockville, MD, USA): T085, T088a; BR243f, BR487 (TNBC); and BR1503b. The following statement was taken from the US Biomax website: 'All tissue is collected under the highest ethical standards with the donor being informed completely and with their consent. We make sure we follow standard medical care and protect the donors' privacy. All human tissues are collected under HIPPA approved protocols'. This work was performed under Minneapolis VA Health Care System Subcommittee on Research Safety protocol number 130601. Slides were deparaffinized by three changes of xylene (10 minutes each). The sections were then rehydrated by passing through graded ethanol $(100 \% \times$ 10 minutes, $100 \% \times 5$ minutes, $95 \% \times 5$ minutes, $80 \% \times$ 5 minutes). Heat-induced antigen retrieval was performed with a citrate-based antigen retrieval solution, pH 6.0 (Rodent Decloaker, Biocare Medical, CA, Concord, USA) for 30 minutes. The endogenous tissue peroxidase activity was quenched with a 3 to $5 \%$ hydrogen peroxide solution in PBS for 10 minutes. The tissue slides were blocked with Background Sniper Reagent (Biocare Medical) in 5\% skim milk for 30 to 60 minutes. The slides were incubated with primary CDK11 antibody (1:50, sc-938; Santa Cruz, CA, USA) overnight at $4^{\circ} \mathrm{C}$. The antigen-antibody complex was detected using Rabbit-on-Rodent-HRP-Polymer for 30 minutes and the betazoid 3,3'-diaminobenzidine peroxidase chromogenic kit (Biocare Medical). Hematoxylin (Vector Lab Burlingame, CA, USA) was used as nuclear counterstain and washed in Clarifier 2 and Bluing reagent (Thermo Scientific Waltham, MA, USA) to obtain better cytoplasm to nuclear contrast. The slides then underwent dehydration processing using graded ethanol, and were washed with xylene before addition of a coverslip with nonaqueous permanent mounting medium (Permount; Fisher Scientific Waltham, MA, USA). Images were captured in bright field as described above.

Scoring for CDK11-positive staining was performed by two independent observers and for each tissue represented the mean of the two observers' scores. CDK11 staining was given an intensity rating ( 0 , no stain; $1+$, faint nuclear stain; $2+$, moderate nuclear stain; $3+$, strong nuclear stain) and a distribution rating representing the percentage of positive cells ( 0 , no positives; $1,<10 \%$ positive; 2,10 to $50 \%$ positive; $3,>50 \%$ positive). The final score per tissue section was the product of the intensity and distribution ratings.

\section{Cell viability assays}

Transfection complexes were formed combining $30 \mathrm{nM}$ single siRNA or $15 \mathrm{nM}$ each of combined siRNAs with $10 \mu \mathrm{l}$ Dharmafect 1 or 2 and OPTI-MEM in a total volume of $400 \mu \mathrm{l}$. After a 20-minute incubation, $1.6 \mathrm{ml}$ antibiotic-free media containing $10 \%$ FBS was mixed in and the total volume added to cells at $50 \%$ confluence on $60 \mathrm{~mm}$ plates. After 5 hours of incubation at $37^{\circ} \mathrm{C} /$ $5 \%$ carbon dioxide, an additional $2 \mathrm{ml}$ complete media were added to each plate. Next day, the cells were trypsinized and cells were plated (8,000 cells for MDA-MB231 and SUM-149; 10,000 cells for MCF-7L ${ }^{\text {TamR }}$ ) into four wells per transfection condition in Primaria 96-well plates coated with $0.33 \mathrm{mg} / \mathrm{ml}$ Matrigel (354234; BD Biosciences), $0.2 \mu \mathrm{g} / \mathrm{ml}$ tenascin-C (CC065; Millipore Billerica, MA, USA) and $0.1 \mu \mathrm{g} / \mathrm{ml}$ fibronectin (F-0895; Sigma). Ninety-six hours following transfection initiation, CellTiter $96^{\circ}$ Aqueous One Assays were performed according to the manufacturer's instructions (Madison, WI, USA). Absorbance values for media alone were subtracted from the experimental values. The data shown represent the results of five experiments for MDA-MB-231, of four experiments for SUM-149, and of two experiments for MCF-7 ${ }^{\text {TamR }}$.

\section{Clonal survival assays}

Cells were transfected as described above, and 48 hours after the first transfection the cells were replated for 50 to $60 \%$ confluence the next day and transfected a second time. Twenty-four hours after the second transfection, the cells were collect using trypsin and plated in triplicate at a concentration of 2,000 cells per $35 \mathrm{~mm}$ plate in standard media. The media were replaced after 4 days, and 7 days after plating the cells were stained with crystal violet for 20 minutes ( $1 \times$ PBS containing $1 \%(\mathrm{v} / \mathrm{v})$ methanol, $1 \%(\mathrm{v} / \mathrm{v})$ formaldehyde and $0.05 \%(\mathrm{w} / \mathrm{v})$ crystal violet), the stain removed, and plates washed by immersion in water with continuous water flow. Plates were air-dried, colonies containing at least 50 cells were counted, and plates were scanned. The data shown represent the results of three replicates per experiment with three experiments performed per cell line.

\section{Immunoblot analysis}

Cell pellets from cultured cells were processed in radioimmunoprecipitation assay buffer and $20 \mu \mathrm{g}$ subjected to $8 \%, 10 \%$ or $12 \%$ Tris-glycine SDS-PAGE as described previously [59]. For lysates from tumors, approximately $0.1 \mathrm{~g}$ frozen tumor tissue was minced and homogenized on ice in $1 \mathrm{ml}$ CSK buffer (10 mM PIPES $\mathrm{pH} 6.8$, $300 \mathrm{mM}$ sucrose, $3 \mathrm{mM} \mathrm{MgCl}_{2}, 1 \mathrm{mM}$ ethylenediamine tetraacetic acid (EDTA), $0.5 \%$ Triton X-100) and centrifuged for 15 minutes at $600 \times g$ at $4^{\circ} \mathrm{C}$. This processing resulted in extraction of the nuclear proteins into the 
supernatant (verified by immunoblot results). The resulting supernatant was quantitated using the Bradford assay (23238; Thermo Scientific), and $30 \mu \mathrm{g}$ each lysate were separated using the NuPAGE 4 to $12 \%$ Bis-Tris and Novex 4 to $12 \%$ Tris-Glycine Midi gel systems (Life Technologies Waltham, MA, USA). The membranes were blocked for 30 minutes with 5\% nonfat milk (1706404; Bio-Rad Hercules, CA, USA) or 5\% bovine serum albumin (A-9647; Sigma) in Tris-buffered saline (pH 7.4) with $0.1 \%$ Tween 20 at room temperature. Antibodies were diluted into fresh blocking buffer according to the manufacturer's recommendations, and the membranes processed as described [59]. Antibodies used were: CDK11 (A300-311A), cyclin L1 (A302-058A), CK2 $\alpha$ (A300-197A) and CK2 $\alpha^{\prime}$ (A300-199A) from Bethyl Laboratories; cyclin L2 (600-401-878) from Rockland Immunochemicals (Limerick, PA, USA); CK2 $\beta$ (sc-12739 and sc-46666) and actin (sc-1616) from Santa Cruz Biotechnology; CDK11 (5524), caspase 3 (9661, 9662), lamin A/C (2032), and BclxL (2762) from Cell Signaling (Beverly, MA, USA); and survivin (AF886) from R\&D Systems (Minneapolis, MN, USA).

\section{Quantitative real-time RT-PCR analysis}

Total RNA was isolated from frozen cell pellets using the RNeasy mini kit (Qiagen Valencia, CA, USA), including the on-column DNase digestion according to the manufacturer's protocol, and quantitated using a NanoDrop spectrophotometer. The Superscript III kit (Invitrogen) was used to synthesize cDNA from total RNA $(0.25 \mu \mathrm{g})$ using oligo-dT primers according to the manufacturer's protocol. FAM TaqMan gene expression probes hs00751002_s1 (CK2 $\alpha)$, hs00176505_m1 (CK2 $\left.\alpha^{\prime}\right)$, hs00414449_m1 (CDK11), and hs01003267_m1 (HPRT-1), TaqMan Fast 2X Mastermix and UNG amperase were from Applied Biosystems, Inc. (Foster City, CA, USA). Reactions were run according to manufacturer's specification using 96-well FAST plates on an ABI 7900HT machine (Applied Biosystems, Inc.). Analyses were performed using the SDS 2.3 ABI software (Applied Biosystems, Inc.) and changes calculated according to the $2^{(-\Delta \Delta \mathrm{Ct})}$ method. HPRT-1 was used as the reference gene for normalization. All results are reported as the average of reactions run in duplicate.

\section{Nanocapsule preparation}

For TBG nanocapsules, a dispersion atomization method was used to package siRNA oligonucleotides into nanocapsules composed of TBG. The modified method of Aukhil and colleagues was used to prepare TBG [60]. All other reagents used were of the highest purity available. Briefly, $250 \mu \mathrm{g}$ siRNA was complexed with $37.5 \mu \mathrm{g}$ spermine $(0.5 \mu \mathrm{g} / \mu \mathrm{l}$; Sigma-Aldrich St. Louis, MO, USA) and dispersed using a water-insoluble surfactant system consisting of $10 \mu \mathrm{g}$ 2,4,7,9-tetramethyl-5-decyn-4,7-diol $(50 \% \mathrm{v} / \mathrm{v})$ in dimethylsulfoxide (Air Products and
Chemicals, Inc. Allentown, PA, USA). Following emulsification into a water-insoluble surfactant dispersed into a water-miscible solvent (dimethylsulfoxide), the siRNA was then inverted by dilution into suspension with addition of $750 \mu \mathrm{l}$ sterile PBS, pH 7.2. The resultant hydrophobic micelles were coated by adsorption to $12.5 \mu \mathrm{g}$ TBG $(1 \mu \mathrm{g} / \mu \mathrm{l})$ dispersed into the solution prior to spray dispersion atomization into a $25 \mathrm{ml} \mathrm{LiCl}$ salt solution $\left(135 \mathrm{mM} \mathrm{Li}^{+}, 9 \mathrm{mM} \mathrm{Ca}^{2+}, 37.5 \mathrm{nM} \mathrm{Sr}^{2+}, 12.5 \mathrm{nM}\right.$ $\left.\mathrm{Mg}^{2+}\right)$. Following incubation at 4 to $6^{\circ} \mathrm{C}$ with rotation in the salt solution for more than 14 hours, the nanocapsules were recovered by centrifugation at 20,000 $\mathrm{x} g$ for 2 hours, and resuspended in PBS containing 10\% lactitol $(\mathrm{w} / \mathrm{v})$ at a theoretical concentration of $1 \mu \mathrm{g} / \mu \mathrm{l}$ for $0.2 \mu \mathrm{m}$ filter sterilization prior to characterization. Average particle diameters were measured from transmission electron microscopy images. Surface charge determinations were confirmed by published methods [61].

\section{Fluorescence-activated cell sorting analysis of cultured cells and xenograft tumors}

MDA-MB-231 $\left(4 \times 10^{5}\right)$ cells and SUM-149 $\left(8 \times 10^{5}\right)$ cells were plated onto $60 \mathrm{~mm}$ plates precoated overnight with $0.25 \mu \mathrm{g} / \mathrm{ml}$ of 3:1 tenascin-C (CC065; Millipore)/ fibronectin-1 (F089; Sigma). The media for MDA-MB-231 cells included $12 \mu \mathrm{l} / \mathrm{ml}$ human low-density lipoprotein to improve nanocapsule uptake. The next morning, media were replaced with $2 \mathrm{ml}$ media containing $125 \mathrm{ng} / \mathrm{ml}$ TBG-dysprosium (Dy). For MDA-MB-231 cells that were treated twice with TBG-Dy, the media were again replaced with $2 \mathrm{ml}$ media containing $125 \mathrm{ng} / \mathrm{ml}$ TBG-Dy 12 hours after the first treatment. The following morning, all cells were 70 to $90 \%$ confluent and were collected and subjected to fluorescence-activated cell sorting (FACS) analysis. A minimum of 10,000 events from each cell transfection or untreated cells were collected. TBG-Dy uptake by cells was determined by gating for Dy fluorescent signal (em 625, Per-CP/Cy5.5 filter). Data were collected and analyzed using a FACS ARIA III (Becton Dickinson San Jose, CA, USA) and FACS DIVA software version 6.0 (BD Biosciences San Jose, CA, USA).

Mice carrying MDA-MB-231 or SUM-149 xenograft tumors initiated in the mammary pad $\left(\sim 300 \mathrm{~mm}^{3}\right)$ were injected with $200 \mathrm{nmol} / \mathrm{kg}$ TBG-Dy by tail vein. Next day, the tumors were collected on ice, finely minced, and incubated at $37^{\circ} \mathrm{C}$ in $1 \times$ collagenase/hyaluronidase (36254; StemCell Tech Vancouver, British Columbia, Canada) in DMEM/F12 with 5\% FBS at a ratio of $10 \mathrm{ml}$ solution per $1 \mathrm{~g}$ tumor. Digestion mixtures were mixed using a transfer pipette every 15 minutes. After $60 \mathrm{mi}-$ nutes, an equal volume of Hank's balanced salt solution (SH30031.02; HyClone) with 2\% FBS was added and the cells centrifuged $350 \times g$ for 5 minutes. Cells were resuspended in $2 \mathrm{ml}$ of $0.05 \%$ trypsin/0.025 mM EDTA and 
incubated for 5 minutes at room temperature. The digestion was stopped by addition of $3 \mathrm{ml}$ DMEM/F12 with 5\% FBS and centrifugation at $350 \times g$ for 5 minutes. The cells were resuspended and continuously pipetted for 1 minute in $2 \mathrm{ml}$ dispase (07913; StemCell Tech) prewarmed to $37^{\circ} \mathrm{C}$ containing $0.1 \mathrm{ml}$ of $1 \mathrm{mg} / \mathrm{ml}$ DNase I (07900; StemCell Tech). Ten milliliters of ice-cold Hank's balanced salt solution with $2 \%$ FBS were added to the digest, and the cells centrifuged at $350 \times g$ for 5 minutes. Cells were resuspended in $5 \mathrm{ml}$ red blood cell lysis buffer (150 mM ammonium chloride, $10 \mathrm{mM}$ potassium bicarbonate, $0.1 \mathrm{mM}$ EDTA), followed by $20 \mathrm{ml}$ ice-cold PBS, and centrifuged at $350 \times g$ for 5 minutes. Cells were resuspended in $5 \mathrm{ml}$ ice-cold Hank's balanced salt solution with $2 \%$ FBS, passed sequentially through $100 \mu \mathrm{m}$ and $40 \mu \mathrm{m}$ cell strainers and centrifuged at $350 \times g$ for $5 \mathrm{mi}-$ nutes. The final cell pellet was resuspended in $2 \mathrm{ml}$ DMEM. FACS analysis was performed as above on the tumor cell suspensions collecting 100,000 events.

\section{5' RNA ligase-mediated RACE}

MDA-MB-231 xenograft and SUM-149 mammary pad tumors from different acute dosing experiments were used for total RNA isolation using TRIzol (Life Technologies), and the quality of RNA was verified by gel electrophoresis. Total RNA $(10 \mu \mathrm{g})$ from the tumors was ligated with $0.5 \mu \mathrm{g}$ RNA adaptor oligomer (5'-cgacuggagcacgaggacacugacauggacugaaggaguagaaa- $3^{\prime}$ ) that contains the forward $5^{\prime}$ adaptor primer binding site in a $20 \mu \mathrm{l}$ reaction using $20 \mathrm{U}$ RNA ligase (New England Biolabs Ipswich, MA, USA) and $40 \mathrm{U}^{\text {RNaseOUT }}{ }^{\mathrm{Tm}}$ (Life Technologies) according to the manufacturer's recommended conditions. The ligated RNA was purified by diafiltration (Ultracel-30 K; Millipore) using conditions for nucleic acids outlined by the manufacturer, and the quality of the ligated RNA product was verified by gel electrophoresis. Eight microliters of the ligated RNA product were reverse transcribed using Superscript III (Life Technologies) and a CDK11 gene-specific primer (5'-ACAAAGTAAGACGAGGAGTTCCGAG-3'), a CK2 $\alpha$ gene-specific primer (5'-CGCTTTCGAGAGTGTCTGCCCAAGA-3'), or a CK2 $\alpha^{\prime}$ gene-specific primer (5'-GGTGTCTGTTCTCA CTATGG-3') designed to hybridize $3^{\prime}$ to the predicted RNAi-mediated cleavage sites in the respective transcripts. The resulting cDNAs $(2 \mu \mathrm{l})$ were used for PCR using the forward RNA adaptor primer (5'-GGACACTGACATGG ACTGAAGGAGTA-3') and the reverse CDK11 (5'-TGGT GGTAAGGTGGAAGCCCGTCTC-3'), CK2 $\alpha$ (5'-TCACT GTGGACAAAGCGTTCCCATC-3'), or CK2 $\alpha^{\prime}$ (5'-TGGA TAAAGTTTTCCCAGCG-3') gene-specific primer. PCR was performed using the Expand High Fidelity system (Roche Applied Science Indianapolis, IN, USA) using dNTP, buffer and enzyme concentrations recommended by the manufacturer. PCR for CK2 $\alpha \alpha^{\prime}$ RACE products was performed using $95^{\circ} \mathrm{C}$ for 3 minutes, 40 cycles of amplification $\left(94^{\circ} \mathrm{C}\right.$ for 45 seconds, $57^{\circ} \mathrm{C}$ for 30 seconds, $72^{\circ} \mathrm{C}$ for 45 seconds), and $72^{\circ} \mathrm{C}$ for 10 minutes. CDK11 RACE products were amplified using $94^{\circ} \mathrm{C}$ for 2 minutes; five cycles of $94^{\circ} \mathrm{C}$ for 30 seconds and $72^{\circ} \mathrm{C}$ for 1 minute; 34 cycles of $94^{\circ} \mathrm{C}$ for $45 \mathrm{sec}-$ onds, $65^{\circ} \mathrm{C}$ for 30 seconds, $72^{\circ} \mathrm{C}$ for 45 seconds; and $72^{\circ} \mathrm{C}$ for 10 minutes. PCR products were analyzed by $2 \%$ agarose Trisborate-EDTA gel electrophoresis stained with ethidium bromide and visualized by UV light. Oligomers were obtained from Integrated DNA Technologies (Coralville, IA, USA).

\section{Mouse xenograft therapeutic acute effect studies}

Female athymic $\mathrm{NCr}$ nude $(\mathrm{Nu} / \mathrm{Nu})$ mice (01B74; National Cancer Institute Frederick, MD, USA) were maintained under pathogen-free conditions. MDA-MB-231 tumors were initiated by subcutaneous injection of $2 \times 10^{6}$ cells in $50 \%$ Matrigel (354234; BD Biosciences) in the mouse flank when mice were 7 to 8 weeks old. Therapy was initiated when tumors reached an average size of $150 \mathrm{~mm}^{3}$, calculated using the formula:

$$
\text { Volume }=(\text { length } \times \text { width } \times \text { width }) / 2
$$

Groups of mice (six to seven mice per group) were subjected to intravenous injection on days 1,4 and 7 with $0.01 \mathrm{mg} / \mathrm{kg}$ TBG-siCDK11, TBG-siCK2, or TBGsiCON1 in Plasma-Lyte-A (Baxter Deerfield, IL, USA). Mice were sacrificed on day 10 , and the tumor, liver, spleen, kidney, ovary, and normal mammary pad were excised, weighed, and snap frozen in liquid nitrogen for protein analysis or were placed in formalin. The animal facilities were approved by the Association for the Assessment and Accreditation of Laboratory Animal Care International and all animal research was performed in strict accordance with the recommendations in the Guide for the Care and Use of Laboratory Animals and with the current regulations and standards of the USDA, the US Department of Health and Human Services, and the National Institutes of Health. Animal experiments were conducted in the Minneapolis VA Health Care System animal facility in accordance with a protocol approved by the Minneapolis VA Health Care System Institutional Animal Care and Use Committee (protocol number 130601).

\section{Image processing}

Immunoblot images from the siRNA-transfectedcultured cells were adjusted in size to align lanes from different comb sizes. Black lines on immunoblots and white lines on agarose gels indicate removal of intervening lanes.

Adobe Photoshop adjustments were made. No gamma changes were made to any image. For immunofluorescence and transmission electron microscopy images, contrast was adjusted to +100 . For immunohistochemistry (IHC) images, brightness was adjusted to +100 and contrast to +50 . 


\section{Statistical analysis}

IHC scores for the CDK11 signal on human breast cancer arrays were determined by two independent observers. The average value was taken for each sample. The comparison between normal tissue and TNBC was conducted using a Wilcoxon rank-sum test and the median and range for each are reported. Mean immunoblot protein levels, cell viability values, and the number of clonal survival colonies were summarized and compared by treatment group using analysis of variance (ANOVA). The mean \pm standard deviation is presented unless otherwise indicated. Mouse tumor volumes on days 7, 9 and 10 (relative to day 1) and primary tumor weights were summarized and compared by treatment group using ANOVA. $P$ values for pairwise comparisons for the above analyses were conservatively adjusted for multiple comparisons using a Bonferroni correction. Differences between mouse weights on day 10 were compared by treatment group using paired $t$ tests. The percentage of Ki67-positive cells was compared by treatment using ANOVA, adjusting for repeated measures within mice. Least-squares means \pm standard errors are presented. $P$ values for these comparisons with the control group were adjusted for multiple comparisons using Dunnett's method.

TCGA breast cancer RSEM-normalized read count RNASeq (v.2, level 3) data were downloaded from The Cancer Genome Atlas data portal (November 2014) and associated metadata (PAM50 RNAseq calls, sample type data) were downloaded from the UCSC Cancer Genome Browser (November 2014). Log $_{2}$-transformed RSEM normalized read counts were used as the final gene expression measurement. ANOVA and Student $t$ tests were used to test for differences in expression for seven genes between basal breast cancer subtype and normal or other subtype primary tumors. $P$ values for pairwise comparisons were conservatively adjusted for multiple comparisons using a Bonferroni correction. $P<0.05$ values are reported and considered statistically significant for all analyses.

\section{Results}

Expression of CDK11 and CK2 protein complex constituents in breast cancer cells

We examined the steady-state protein expression levels for CDK11 and CK2 protein complex members in breast cancer cell lines representing a range of subtypes. We also included nontransformed, immortalized cell lines (see Table 1). CDK $11^{\mathrm{p} 110}$ and partner cyclins $\mathrm{L} 1 \alpha$ and $\mathrm{L} 2 \alpha$ were well expressed in these cell lines, with the exception of SUM-190 (Figure 1A). CDK11 ${ }^{\mathrm{p} 110}$ was detected in SUM-190 cells upon longer exposure. In these breast cancer cell lines, detection of CDK11 displayed the prominent $\mathrm{CDK} 11^{\mathrm{p} 110}$ isoform along with lesser expression of slightly smaller alternatively spliced isoforms, as has been observed previously [8,9]. Cyclin L1 $\alpha$ is detected as a doublet or triplet when using radioimmunoprecipitation assay buffer, which can be observed in SUM-190 lysate due to the lower expression level. Cyclin L $2 \alpha$ was detected as a single band. CK $2 \alpha$ and CK $2 \alpha^{\prime}$ proteins were simultaneously detected and demonstrated strong expression levels. The expression level of $\mathrm{CK} 2 \alpha^{\prime}$ relative to $\mathrm{CK} 2 \alpha$ was unusually high in the inflammatory breast cancer cells, suggesting a possible role for $\mathrm{CK} 2 \alpha^{\prime}$ in inflammatory breast cancer. CK2 $\beta$ was moderately expressed in all cell lines.

Intracellular protein expression patterns for CDK11 and CK2 $\alpha \alpha^{\prime}$ in nontransformed MCF-10A cells were examined by indirect immunofluorescence (Figure 1B). CDK11 proteins were detected mainly in the nuclei with prominent transcription and pre-mRNA splicing speckle distribution and more diffuse nucleoplasmic localization, as has been seen in nonbreast cell lines [9]. CK $2 \alpha$ and $C K 2 \alpha^{\prime}$ proteins were localized in both nuclei and cytoplasm with a much stronger, finely speckled nuclear signal than cytoplasmic signal. CDK11 protein localization in TNBC cells was also evaluated and found to mirror that observed in the nontransformed cells (Figure 1B).

Table 1 Characteristics of breast cancer cell lines

\begin{tabular}{lllllll}
\hline Cell line $^{\text {a }}$ & Transformed & Molecular subtype & Histological pathology & ER expressed & PR expressed & Her2 amplified \\
\hline MCF-10A & No & Basal & Fibrocystic & No & No & No \\
MCF-12A & No & Basal & Fibrocystic & No & No & Yes \\
BT-474 & Yes & Luminal B & DC & Yes & Yes & No \\
MCF-7 & Yes & Luminal A & AC & Yes & Yes & No \\
MCF-7L ${ }^{\text {TamR }}$ & Yes & Luminal A & AC & Yes & Yes & No \\
MDA-MB-231 & Yes & Basal & AC & No & No & No \\
MDA-MB-468 & Yes & Basal & AC & No & No & No \\
SUM-149 & Yes & Basal & IBC & No & No & Yes \\
SUM-190 & Yes & Basal & BC & N
\end{tabular}

AC, adenocarcinoma; DC, ductal carcinoma; ER, estrogen receptor; IBC, inflammatory breast cancer; PR, progesterone receptor; Her2, human epidermal growth factor receptor $2 .{ }^{\mathrm{a}} \mathrm{MCF}-10 \mathrm{~A}$ and MCF-12A are spontaneously immortalized cells. ${ }^{\mathrm{b}}$ Original tissue or tumor. 


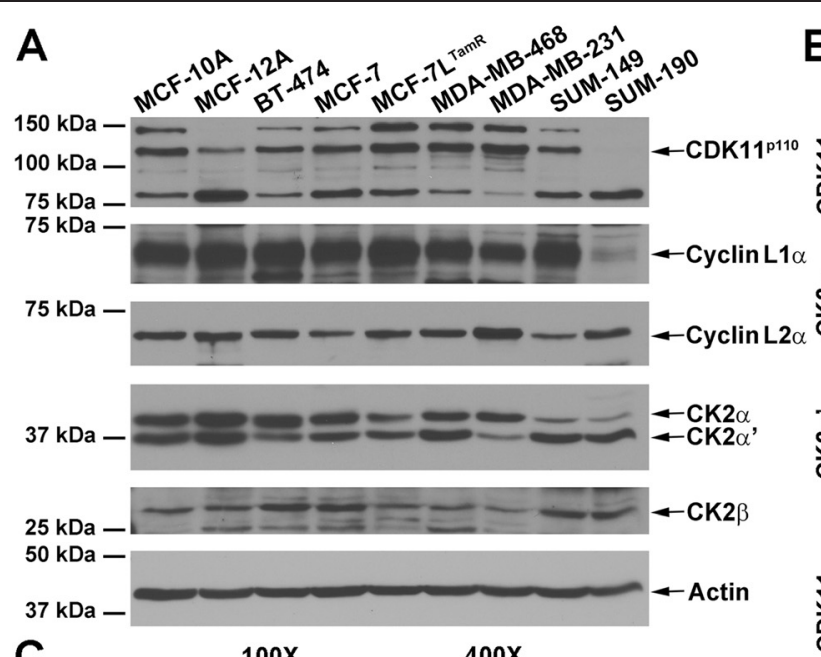

C

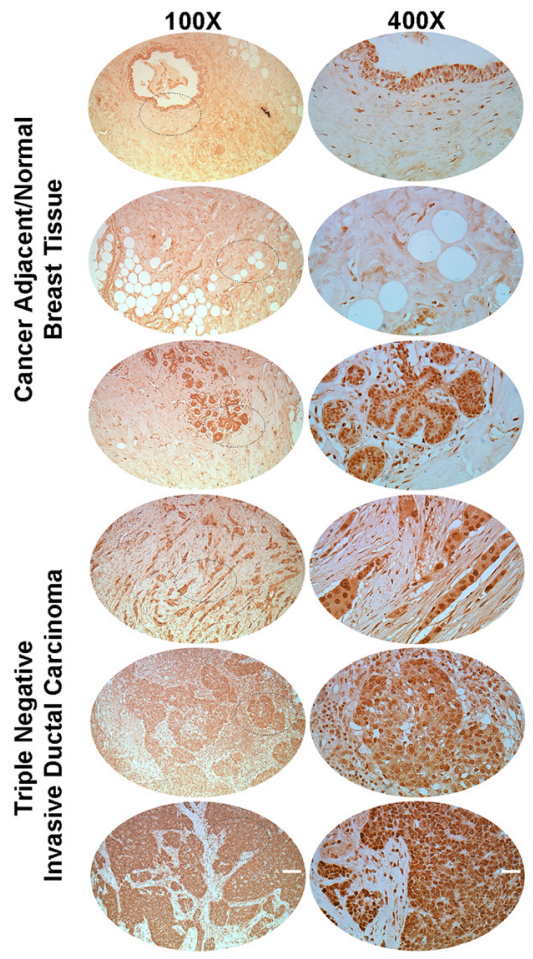

B

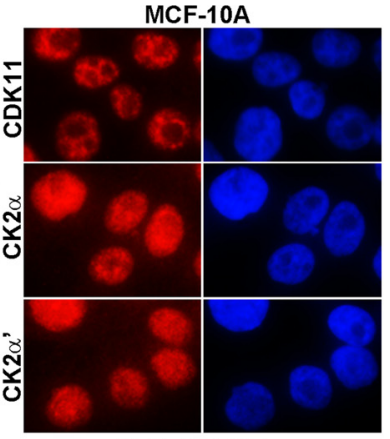

MDA-MB-231

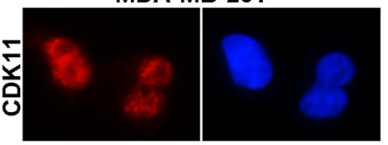

SUM-149

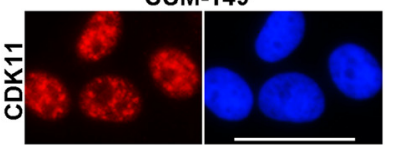

D

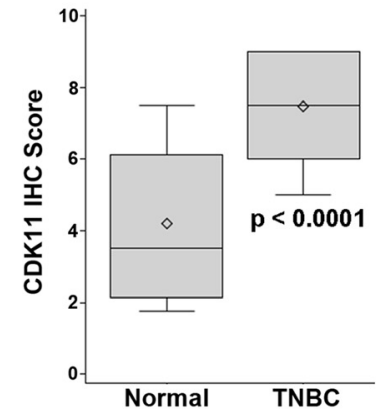

Figure 1 Expression of CDK11 and CK2 protein complex members in untransformed and malignant breast cells. (A) Immunoblot analysis of cultured breast cell lines, as indicated above the blots. Proteins detected are indicated on the right side of the blots. Actin signal was used as the loading control. (B) Indirect immunofluorescent detection of CDK11, CK2a, and CK2a' (red color) in breast cell lines. Cell lines are indicated above each set of images and proteins detected are indicated on the left side of the images. Blue, 4',6-diamidino-2-phenylindole-stained nuclei. Scale bar: $100 \mu \mathrm{m}$. (C) Immunohistochemical detection of CDK11 proteins in human normal and malignant breast tissue. Type of breast tissue indicated on the left side of the images. Magnification indicated above the images; dotted ellipse, portion of the $100 \times$ image that is shown at 400x. Scale bars: $400 \mu \mathrm{m}$ for $100 \times$ and $100 \mu \mathrm{m}$ for 400x images. (D) Human microarray tissues stained for CDK11 were scored by two independent observers. The average value was taken and the results plotted for normal $(n=16)$ versus triple-negative breast cancer (TNBC; $n=44)$ tissues. Box, first to third (Q1 to Q3) quartiles; diamond, mean; line inside box, median; whiskers, minimum and maximums of data range. CDK, cyclin-dependent kinase; CK2, casein kinase 2.

\section{CDK11 and CK2 mRNA expression in triple-negative} breast cancer cells

We investigated how transcript expression related to protein expression in the nontransformed and TNBC cells for CDK11, CK $2 \alpha$ and CK $2 \alpha^{\prime}$. Data from quantitative real-time RT-PCR are summarized in Table 2. In general, protein expression and mRNA expression levels were similarly related for the TNBC cells. For example, in MDA-MB-468 cells roughly equal amounts of $\mathrm{CK} 2 \alpha$ and $\mathrm{CK} 2 \alpha^{\prime}$ protein levels are detected 
Table 2 mRNA expression levels in nontransformed and malignant breast cells ${ }^{a}$

\begin{tabular}{llll}
\hline Cell line & CDK1 $^{\mathbf{b}}$ & CK2 $\boldsymbol{a}$ & CK2 $^{\prime}$ \\
\hline MCF-10A & $1.53 \pm 0.04$ & $2.90 \pm 0.35$ & $5.19 \pm 0.36$ \\
MCF-12A & $1.38 \pm 0.07$ & $1.91 \pm 0.17$ & $1.05 \pm 0.03$ \\
MDA-MB-231 & $0.96 \pm 0.10$ & $2.91 \pm 0.48$ & $0.40 \pm 0.004$ \\
MDA-MB-468 & $0.87 \pm 0.11$ & $3.18 \pm 0.06$ & $2.91 \pm 0.39$ \\
SUM-149 & $0.31 \pm 0.001$ & $0.66 \pm 0.08$ & $1.84 \pm 0.01$ \\
\hline
\end{tabular}

Data presented as mean \pm standard error. ${ }^{a}$ mRNA expression normalized to

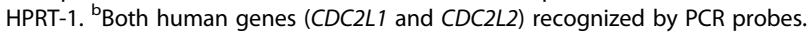

(Figure 1A), and likewise roughly equal amounts of the corresponding mRNA transcripts are expressed. In the nontransformed MCF-10A and MCF-12A cells, equal amounts of $C K 2 \alpha$ and $C K 2 \alpha^{\prime}$ proteins are expressed but the relative amounts of their corresponding mRNAs differ. For CDK11, more mRNA is expressed in MDAMB-231 and MDA-MB-468 cells than in SUM-149 cells, which matches the relative amounts of $\mathrm{CDK} 11^{\mathrm{p} 110}$ protein detected. In contrast, the nontransformed MCF$10 \mathrm{~A}$ and MCF-12A breast cells expressed roughly 1.6fold greater CDK11 mRNA relative to MDA-MB-231 and MDA-MB-468, but expressed equal or lesser amounts of protein.

\section{CDK11 proteins are highly expressed in human triple-} negative breast cancer tissue

We also examined CDK11 protein expression in human normal and malignant breast tissue using tissue microarrays. The antibody used for detection of CDK11 in the tissues recognizes the carboxy terminus of both CDK $11^{\mathrm{p} 110}$ and $\mathrm{CDK} 11^{\mathrm{p} 58}$ isoforms; however, because $\mathrm{CDK} 11^{\mathrm{p} 58}$ is typically only detected in cells transitioning from $\mathrm{G} 2$ to mitosis cell cycle phases, the vast majority of CDK11 detected in tissue array samples represents the CDK $11^{\mathrm{p} 110}$ isoforms. IHC CDK11 staining specificity was verified by comparing results using two different commercial antibodies on human xenograft tumor tissues (data not shown). Upon staining of the tissue microarrays, CDK11 signal was observed in both malignant and normal tissue (Figure 1C). Unlike cells proliferating in culture, cells in normal breast tissue are less likely to be actively proliferating; however, the $\mathrm{CDK} 11^{\mathrm{p} 110}$ isoforms have function in nondividing cells as well as actively proliferating cells, and thus were detected in normal breast epithelial cells as well as malignant cells. CDK11 protein expression in the breast tissues, as measured by IHC, was evaluated; the median score in TNBC was 7.5 (range 5.0 to 9.0) and was statistically significantly greater than the score in normal breast tissue (3.5 (range 1.8 to 7.5$)$ ) (Figure 1D). Overall, CDK11 staining was predominantly nuclear in both normal and TNBC tissues, with higher intensity and higher percentage of positive cells in TNBC $(P<0.0001)$. The higher level of CDK11 protein signal in human TNBC observed here compared with normal breast is in agreement with the shift from moderate expression in breast glandular and myoepithelial cells to moderate-strong expression in breast cancer as documented on the Human Protein Atlas website $[62,63]$.

IHC results for increased $\mathrm{CK} 2 \alpha$ protein expression, especially in the nucleus, and correlation with metastatic risk in human breast cancer tissues have been published previously $[44,64]$, and specific staining for CK2 $2 \alpha^{\prime}$ in human TNBC tissues was not performed here.

\section{Expression of CDK11 and CK2 protein complex genes in human breast cancer subtypes}

Given the increased intensity of CDK11 protein signal in the TNBC tissues, we examined the mRNA transcript expression levels for CDK11 (CDC2L1, CDC2L2) using The Cancer Genome Atlas RNAseq data. We performed the same analysis for cyclin L1 (CNCL1), cyclin L2 (CNCL2), CK $2 \alpha$ (CSNK2A1), CK2 $\alpha^{\prime}$ (CSNK2A2), and CK2 $\beta$ (CSNK2B). We used the PAM50 subtypes to compare transcript expression in basal-subtype breast cancer with normal breast tissue and with the other breast cancer subtypes. The data are summarized in Figure 2 and Table 3. CDK11A showed no significant differences in mRNA expression compared with normal breast and with other breast cancer subtype tissues, and CDK11B expression in the basal subtype demonstrated a significant increase in mRNA expression relative to luminal B. Cyclin L1 mRNA expression was significantly lower in basal than normal tissue, but significantly higher than all other breast cancer subtypes. Cyclin L2 transcript expression was also significantly lower in basal breast cancer than in normal breast. CK $2 \alpha$ mRNA expression was significantly higher in the basal subtype than in normal tissue and the luminal A subtype. CK2 $\alpha^{\prime}$ transcript levels were the same in the basal subtype as in normal tissue and significantly higher in the basal subtype than in HER2, luminal A, and luminal B cancers. Finally, CK2 $\beta$ mRNA expression in basal breast cancer was significantly higher than normal tissue and all other breast cancer subtypes. In these RNAseq analyses, the basal subtype was used as a surrogate for TNBC; additionally, we found highly similar expression patterns when comparing TNBC with all other biomarker breast cancers using microarray datasets found on Oncomine [65] (data not shown).

siRNA-mediated downregulation of CDK11 and CK2 in breast cancer cells induces death signaling, decreases cell viability, and inhibits clonal survival

We used siRNA sequences previously validated for both CDK11 gene transcripts, located $3^{\prime}$ to the CDK11 ${ }^{\mathrm{p} 58}$ 


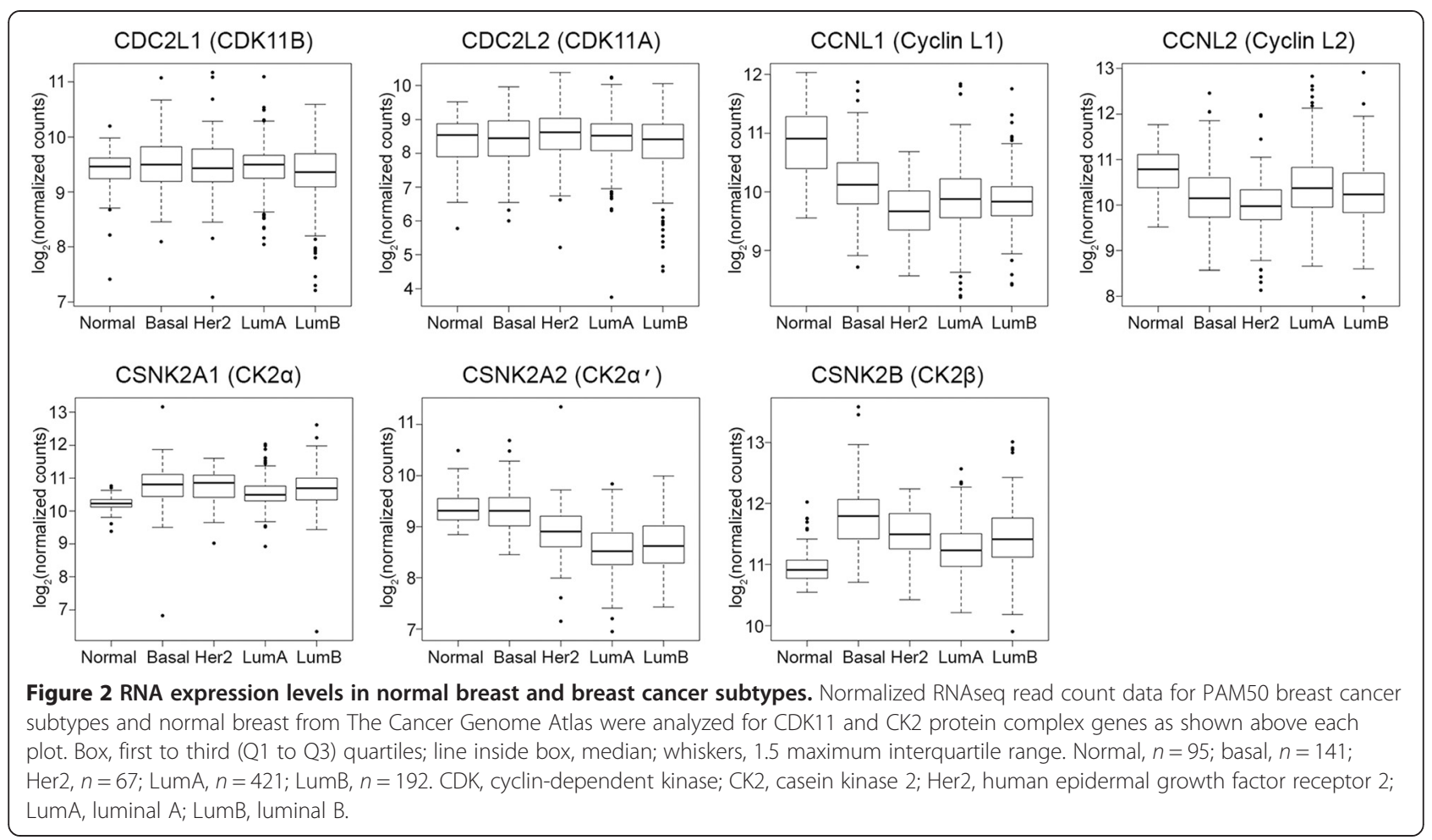

internal ribosomal entry site, and for both $\mathrm{CK} 2 \alpha$ and CK $2 \alpha^{\prime}$ catalytic subunit gene transcripts to test the effects of downregulation of CK2 alone, CDK11 alone, or combined CK2 and CDK11 in breast cancer cells $[2,30]$. Transfection of siCDK11 efficiently reduced CDK11 ${ }^{\text {p110 }}$ protein expression in MDA-MB-231 and SUM-149 cells by 72 hours post transfection (Figure 3 ). CDK $11^{\mathrm{p} 58}$ was not detectable in these asynchronously growing cells. Loss of CDK11 expression did not have a consistent effect on cyclin L $1 \alpha$ or cyclin $\mathrm{L} 2 \alpha$ expression levels; however, downregulation of CDK11 resulted in faster migration of the cyclin $\mathrm{L} 2 \alpha$ protein. We also observed that transfection of cultured cells frequently caused increased detection of cyclin L1 $\alpha$ protein. Transfection of siCK2 significantly reduced expression of $\mathrm{CK} 2 \alpha$ and $\mathrm{CK} 2 \alpha^{\prime}$ at 72 hours in MDA-MB-231 and SUM-149 cells; concomitantly, CK2 $\beta$ expression levels were also significantly reduced (Figure 3 ). Interestingly, loss of CK2 also resulted in altered cyclin L2 $\alpha$ migration. Loss of CK2 and/or CDK11 expression resulted in modulation of cell death associated gene expression at 96 hours post transfection. Reduced detection of fulllength caspase 3 protein was observed (Figure 3), and activated caspase 3 cleavage products were also sometimes detected (data not shown). Decreased full-length lamin $\mathrm{A} / \mathrm{C}$ and appearance of cleaved lamin $\mathrm{A} / \mathrm{C}$ products were also observed (data not shown). Loss of Bcl-xL expression was more evident with knockdown of CDK11 than CK2 in both cell lines, whereas slight loss of survivin expression was mainly seen following combined kinase knockdown. Quantitative analysis of protein expression is summarized in Table 4.

The specificity of the CDK11 and CK2 siRNAs for targeting the intended genes was examined by quantitative real-time RT-PCR. MDA-MB-231 and SUM-149 cells were transfected with $30 \mathrm{nM}$ siRNAs (siCDK11, siCK2, siControl), cells were collected at 24 hours post transfection, and quantitative real-time RT-PCR was performed. CDK11 mRNA was decreased to 59\% in both cell lines by siCDK11 transfection (Table 5). Strong downregulation of CK $2 \alpha$ and $\mathrm{CK} 2 \alpha^{\prime}$ mRNAs to less than $20 \%$ was observed in both TNBC cell types. Neither siCK2 nor siCDK11 transfections resulted in off-target decreased expression of CDK11 or CK2 $\alpha \alpha^{\prime}$ mRNAs, respectively (Table 5). Decreased protein expression for the targeted mRNAs was observed at 48 hours (data not shown).

The viability of cells following a single transfection of siCDK11, siCK2, or combined siCK2/siCDK11 was measured in MDA-MB-231, SUM-149, and MCF-7 ${ }^{\text {TamR }}$ cell lines using the CellTiter $96^{\circ}$ Aqueous One assay. Transfected cells were plated into wells coated with Matrigel, tenascin- $\mathrm{C}$, and fibronectin to more closely mimic the in vivo tumor cell environment. Significant reductions in cell viability were observed for all three transfection types for SUM-149 and MCF-7 ${ }^{\text {TamR }}$ cells; whereas significant reductions in viability were observed in MDAMB-231 cells for siCDK11 and siCK2/siCDK11, but not siCK2 alone (Figure 4A). Given that visual observation 
Table 3 mRNA expression levels in normal and breast cancer subtypes

\begin{tabular}{|c|c|c|c|}
\hline Gene & Subtype or normal ${ }^{a}$ & $\log _{2}\left(\right.$ normalized counts) ${ }^{b}$ & Comparison with basal $^{c}$ \\
\hline \multirow[t]{5}{*}{ CDC2L1 } & Normal & $9.39 \pm 0.38$ & 0.90 \\
\hline & Basal & $9.51 \pm 0.5$ & N/A \\
\hline & Her2 & $9.45 \pm 0.61$ & 1 \\
\hline & Luminal A & $9.46 \pm 0.4$ & 1 \\
\hline & Luminal B & $9.33 \pm 0.57$ & 0.049 \\
\hline \multirow[t]{5}{*}{ CDC2L2 } & Normal & $8.35 \pm 0.76$ & $-{ }^{d}$ \\
\hline & Basal & $8.37 \pm 0.79$ & N/A \\
\hline & Her2 & $8.49 \pm 0.84$ & - \\
\hline & Luminal A & $8.44 \pm 0.69$ & - \\
\hline & Luminal B & $8.24 \pm 0.95$ & - \\
\hline \multirow[t]{5}{*}{ CCNL1 } & Normal & $10.82 \pm 0.58$ & $1.37 \times 10^{-14}$ \\
\hline & Basal & $10.15 \pm 0.56$ & N/A \\
\hline & Her2 & $9.7 \pm 0.49$ & $9.68 \times 10^{-7}$ \\
\hline & Luminal A & $9.87 \pm 0.55$ & $2.17 \times 10^{-5}$ \\
\hline & Luminal B & $9.85 \pm 0.49$ & $2.10 \times 10^{-5}$ \\
\hline \multirow[t]{5}{*}{ CCNL2 } & Normal & $10.79 \pm 0.48$ & $1.90 \times 10^{-11}$ \\
\hline & Basal & $10.2 \pm 0.71$ & $\mathrm{~N} / \mathrm{A}$ \\
\hline & Her2 & $10 \pm 0.73$ & 1 \\
\hline & Luminal A & $10.38 \pm 0.7$ & 0.21 \\
\hline & Luminal B & $10.28 \pm 0.7$ & 1 \\
\hline \multirow[t]{5}{*}{ CSNK2A1 } & Normal & $10.22 \pm 0.2$ & $5.50 \times 10^{-15}$ \\
\hline & Basal & $10.74 \pm 0.64$ & N/A \\
\hline & Her2 & $10.75 \pm 0.51$ & 1 \\
\hline & Luminal A & $10.53 \pm 0.39$ & $9.20 \times 10^{-3}$ \\
\hline & Luminal B & $10.68 \pm 0.61$ & 1 \\
\hline \multirow[t]{5}{*}{ CSNK2A2 } & Normal & $9.36 \pm 0.3$ & 1 \\
\hline & Basal & $9.3 \pm 0.39$ & N/A \\
\hline & Her2 & $8.92 \pm 0.56$ & $3.89 \times 10^{-5}$ \\
\hline & Luminal A & $8.56 \pm 0.45$ & $2.06 \times 10^{-49}$ \\
\hline & Luminal B & $8.64 \pm 0.47$ & $2.99 \times 10^{-33}$ \\
\hline \multirow[t]{5}{*}{ CSNK2B } & Normal & $10.96 \pm 0.28$ & $3.03 \times 10^{-38}$ \\
\hline & Basal & $11.78 \pm 0.5$ & N/A \\
\hline & Her2 & $11.52 \pm 0.39$ & $1.91 \times 10^{-3}$ \\
\hline & Luminal A & $11.25 \pm 0.42$ & $4.04 \times 10^{-22}$ \\
\hline & Luminal B & $11.43 \pm 0.54$ & $8.24 \times 10^{-8}$ \\
\hline
\end{tabular}

Her2, human epidermal growth factor receptor 2 ; N/A, not applicable. ${ }^{\mathrm{a}}$ Normal, $n=95$; basal, $n=141$; Her2, $n=67$; luminal $\mathrm{A}, n=421$; luminal $\mathrm{B}, n=192$. ${ }^{\mathrm{b}} \mathrm{RNAseq}$ data from The Cancer Genome Atlas expressed as mean \pm standard deviation. 'Comparison with basal subtype, $P$ value with Bonferroni correction; significant $P$ values in bold type. ${ }^{\mathrm{d}}$ Analysis of variance comparing CDC2L2 expression across subtypes revealed no significant differences, so no pairwise $t$ tests were performed.

of cells and immunoblot data suggested that MDA-MB231 cells were, in fact, dying due to siCK2 transfection, we decided to use a different assay to evaluate cell survival following transfection of the different siRNAs. The clonal survival assay was employed in which MDA-MB231 and SUM-149 cells were transfected twice with the siRNA combinations - once on day 1 and once on day
4. Twenty-four hours after the second transfection, the cells were collected using trypsin and plated in triplicate at 2,000 cells per $35 \mathrm{~mm}$ plate. After 7 days of incubation, the cell colonies were stained with crystal violet and counted. Downregulation of CDK11, CK2, or combined CDK11/CK2 protein expression resulted in highly significant loss of cell survival in SUM-149 cells and 


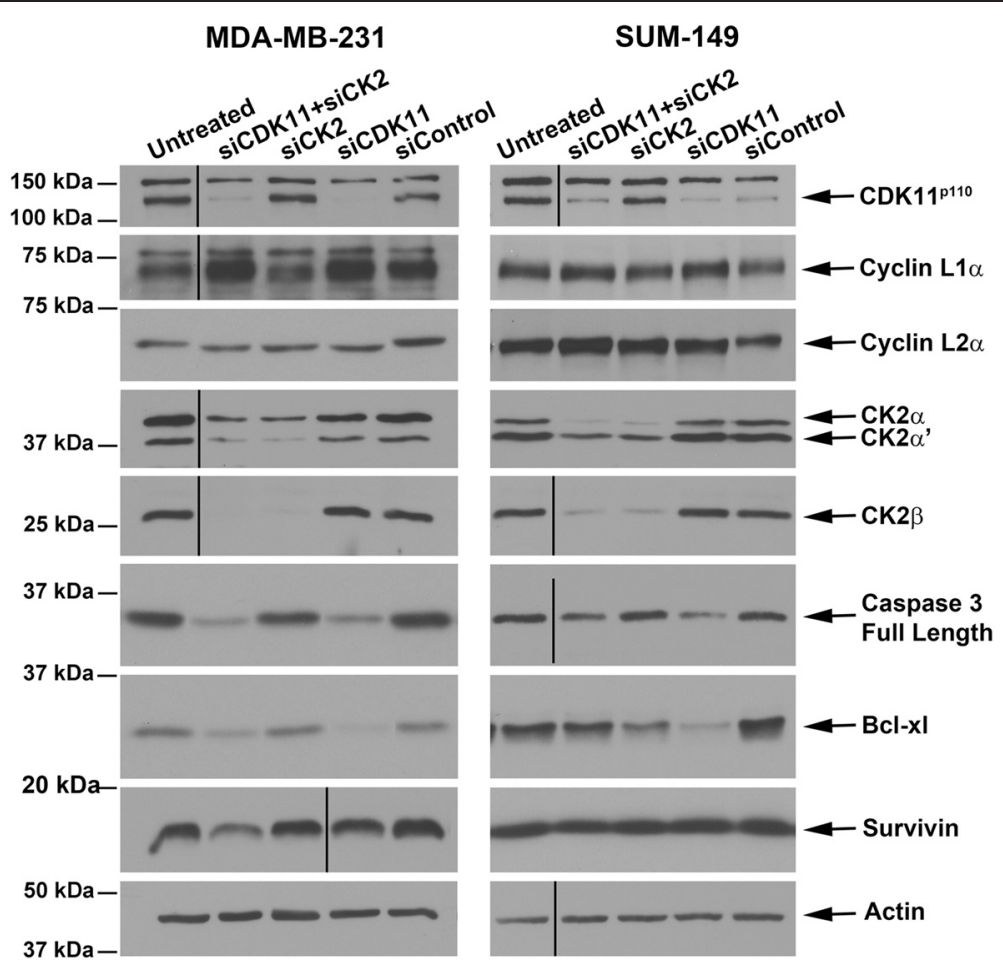

Figure 3 Immunoblot analyses following small interfering RNA-mediated downregulation of CDK11 and CK2 in breast cancer cells. Immunoblot analysis of MDA-MB-231 and SUM-149 cell lysates following small interfering RNA (siRNA) transfection. Transfected siRNAs are indicated above the blots, proteins detected are indicated on the right side of the blots. CDK1 ${ }^{\text {p110 }}$, cyclin L1a, cyclin L2a, and CK2aa' $\beta$ lysates are 72 hours post transfection; caspase 3, Bcl-xL, and survivin lysates are 96 hours post transfection. Actin signal was used as the loading control. CDK, cyclin-dependent kinase; CK2, casein kinase 2.

almost complete loss of cell survival in MDA-MB-231 cells (Figure 4B). Representative crystal violet stained colonies are shown in Figure 4C.

\section{Tenfibgen nanocapsules enter cultured and xenograft triple-negative breast cancer cells}

To evaluate the in vivo effects on tumor growth of treatment with siCDK11 or siCK2, we employed a unique sub-50 $\mathrm{nm}$ size (that is, $<50 \mathrm{~nm}$ ) TBG-based nanocapsule that is capable of protected intracellular delivery of siRNA cargos in a malignant cell-specific manner [1-3]. Figure 5A and Table 6 define the physical characteristics of the TBG nanocapsules used in the therapeutic treatment studies. For the purpose of quantifying nanocapsule uptake, we used TBG nanocapsules containing a dysprosium dextran cargo. Dy is a fluorescent lanthanide element. To establish the feasibility of FACS analysis for Dy, MDA-MB-231 and SUM-149 cells were grown on combined tenascin- $\mathrm{C}$ and fibronectin matrix, treated in culture with TBG-Dy nanocapsules, and collected 1 day later for FACS analysis of the Dy content. Untreated cells were used to establish the analysis gate. Dy-positive cells totaled $14.4 \%$ in the MDA-MB-231 cells (Figure 5B, left panel and Table 7) and 13.1\% in the SUM-149 cells (Table 7). Additionally, MDA-MB-231 cells were treated once in the morning and again 12 hours later to evaluate whether further uptake could be achieved. A 1.49-fold increase in Dy-positive cells was achieved by a second treatment (Figure 5B, right panel and Table 7).

Having established TBG-Dy FACS methodology, we wished to quantitate the delivery of TBG nanocapsules to tumor cells in vivo after one intravenous treatment. Mice carrying MDA-MB-231 or SUM-149 mammary pad xenograft tumors were injected via the tail vein with TBG-Dy nanocapsule. After 24 hours, tumors were collected from the TBG-Dy-injected mice as well as non-injected control mice and subjected to dissociation. FACS analysis for Dy signal was performed, using the naive tumor cells to establish the gate (Figure 5C, left panels). After just one injection, an average of $33.9 \pm 4.7 \%$ of the SUM-149 tumor cells was Dy-positive and $11.0 \%$ of the MDA-MB-231 tumor cells were positive for Dy signal (Figure 5C, right panels and Table 7).

Treatment with TBG-siCDK11 or TBG-siCK2 nanocapsules causes MDA-MB-231 xenograft tumor shrinkage and loss of proliferation

To demonstrate specific efficacy of CDK11 or CK2 targeting in vivo via TBG siRNA nanocapsules, we performed an acute response study in which nude mice 
Table 4 Protein expression levels following small interfering RNA transfection

\begin{tabular}{|c|c|c|c|c|c|c|c|c|c|c|}
\hline & siRNA & CDK11 & Cyclin L1a & Cyclin L2a & CK2a & CK2 $a^{\prime}$ & CK2 $\beta$ & $\begin{array}{l}\text { Caspase } 3 \text { - full } \\
\text { length }\end{array}$ & Bcl-xL & Survivin \\
\hline \multirow[t]{7}{*}{ MDA-MB-231 } & siCDK11/CK2 & $0.09 \pm 0.02$ & $3.07 \pm 1.56$ & $0.73 \pm 0.53$ & $0.07 \pm 0.08$ & $0.05 \pm 0.06$ & $0.03 \pm 0.03$ & $0.45 \pm 0.17$ & $0.40 \pm 0.38$ & $0.73 \pm 0.53$ \\
\hline & & $P<0.0001$ & & & $P<0.0001$ & $P=0.001$ & $P<0.0001$ & & & \\
\hline & siCK2 & $0.98 \pm 0.17$ & $1.82 \pm 0.67$ & $0.78 \pm 0.45$ & $0.07 \pm 0.07$ & $0.05 \pm 0.06$ & $0.06 \pm 0.04$ & $0.85 \pm 0.57$ & $0.62 \pm 0.10$ & $0.85 \pm 0.33$ \\
\hline & & & & & $P<0.0001$ & $P=0.001$ & $P<0.0001$ & & & \\
\hline & siCDK11 & $0.04 \pm 0.07$ & $2.38 \pm 0.18$ & $0.91 \pm 0.49$ & $0.88 \pm 0.17$ & $1.13 \pm 0.18$ & $1.05 \pm 0.15$ & $0.57 \pm 0.23$ & $0.24 \pm 0.05$ & $0.79 \pm 0.21$ \\
\hline & & $P<0.0001$ & & & & & & & $P=0.022$ & \\
\hline & siControl & $0.90 \pm 0.04$ & $1.77 \pm 0.31$ & $1.44 \pm 0.62$ & $1.09 \pm 0.10$ & $0.98 \pm 0.26$ & $1.14 \pm 0.04$ & $0.99 \pm 0.07$ & $0.93 \pm 0.32$ & $1.02 \pm 0.20$ \\
\hline \multirow[t]{7}{*}{ SUM-149 } & siCDK11/CK2 & $0.44 \pm 0.04$ & $1.05 \pm 0.12$ & $1.30 \pm 0.48$ & $0.06 \pm 0.05$ & $0.27 \pm 0.10$ & $0.25 \pm 0.14$ & $0.45 \pm 0.17$ & $0.31 \pm 0.21$ & $0.77 \pm 0.33$ \\
\hline & & $P<0.0001$ & & & $P<0.0001$ & $P=0.0004$ & $P=0.001$ & $P=0.036$ & $P=0.034$ & \\
\hline & siCK2 & $0.86 \pm 0.13$ & $0.93 \pm 0.18$ & $1.31 \pm 0.52$ & $0.08 \pm 0.07$ & $0.31 \pm 0.23$ & $0.14 \pm 0.07$ & $0.55 \pm 0.34$ & $0.73 \pm 0.12$ & $1.02 \pm 0.10$ \\
\hline & & & & & $P<0.0001$ & $P=0.0007$ & $P=0.0004$ & & & \\
\hline & siCDK11 & $0.40 \pm 0.16$ & $1.04 \pm 0.05$ & $1.00 \pm 0.19$ & $1.19 \pm 0.14$ & $0.96 \pm 0.12$ & $0.77 \pm 0.26$ & $0.62 \pm 0.23$ & $0.54 \pm 0.31$ & $0.98 \pm 0.18$ \\
\hline & & $P<0.0001$ & & & & & & & & \\
\hline & siControl & $0.89 \pm 0.12$ & $0.89 \pm 0.26$ & $0.90 \pm 0.87$ & $1.36 \pm 0.27$ & $1.05 \pm 0.29$ & $0.88 \pm 0.17$ & $0.92 \pm 0.24$ & $1.08 \pm 0.30$ & $0.89 \pm 0.22$ \\
\hline
\end{tabular}

All values normalized to actin expression and expressed relative to untreated cells as mean \pm standard deviation. $P$ values are listed underneath the corresponding protein expression value for comparison with untreated cells if $P<0.05$. CDK, cyclin-dependent kinase; CK2, casein kinase 2; siRNA, small interfering RNA.

carrying TNBC MDA-MB-231 flank tumors were treated three times by tail vein injection with $0.01 \mathrm{mg} / \mathrm{kg}$ of TBG-siCDK11, TBG-siCK2, or TBG-siCON1 (a control nontargeting siRNA [57]). This dose and schedule was chosen based on studies performed in prostate cancer models (unpublished data). Tumors were collected 10 days after initiation of treatment, and showed significant reduction of tumor volume below the starting volume for TBG-siCDK11 $(P=0.001)$ and just above the starting volume for TBG-siCK2 $(P=0.026$, Figure 6A). Tumor weights were also reduced in TBG-siCDK11treated $(P=0.030)$ and TBG-siCK2-treated mice compared with TBG-siCON1-treated mice (Figure 6B). No significant changes in mouse weights were observed following treatment with any of the nanocapsules (Figure 6C). Finally, tumor proliferation was evaluated by Ki-67 IHC and both TBG-siCDK11-treated $(P=0.004)$ and TBG-siCK2-treated tumors demonstrated reduced proliferation rates (Figure 6D).

Table 5 mRNA expression levels in small interfering RNA transfected cells

\begin{tabular}{lllll}
\hline & MDA-MB-231 & & SUM-149 & \\
\hline & siCDK11 & siCK2 & siCDK11 & siCK2 \\
CDK11 & 0.59 & 1.36 & 0.59 & 0.98 \\
CK2a & 2.09 & 0.15 & 1.37 & 0.13 \\
CK2a' & 1.48 & 0.19 & 1.18 & 0.16 \\
\hline
\end{tabular}

mRNA expression at 24 hours normalized to HPRT-1 and expressed relative to siControl; mean of duplicate wells. si, small interfering.
Treatment with TBG-siCDK11 or TBG-siCK2 induces RNAinduced silencing complex cleavage of the relevant mRNA transcripts in TNBC orthotopic xenograft tumors

RNA from TBG-siCDK11-treated and TBG-siCK2treated tumors was analyzed using the modified 5' RACE technique to detect potential cleavage products. Because there was not enough MDA-MB-231 TBGsiCDK11-treated tumor remaining for this analysis, we used SUM-149 mammary pad tumors from another study. The data indicated that RNA-induced silencing complex (RISC) cleavage products were detected for CDK11 and for CK2 $\alpha$ mRNAs in tumors specifically following TBG-siCDK11 and TBG-siCK2 treatments, respectively (Figure 7A). No CDK11 or CK2 cleavage products were detected in TBG-siCON1-treated tumors. RISC cleavage products for CK $2 \alpha$ were also detected in MDA-MB-231 xenograft tumors (data not shown). No CK $2 \alpha^{\prime}$ cleavage products were detected in either SUM149 or MDA-MB-231 TBG-siCK2-treated tumors.

TBG-siCDK11-treated and TBG-siCK2-treated tumors show loss of target protein expression and induction of death signaling

Tumor lysates were subjected to immunoblot analysis to evaluate the effects of nanocapsule treatment on target gene expression (Figure 7B). TBG-siCDK11 treatment resulted in $\mathrm{CDK} 11^{\mathrm{p} 110}$ protein expression reduced to $66 \%$ relative to TBG-siCON1 $(P=0.002)$, cyclin L1 $\alpha$ increased to $216 \%(P=0.040)$, and cyclin $\mathrm{L} 2 \alpha$ reduced to $87 \%$ (Figure $7 C$ ). Cyclin L $2 \alpha$ migration was slightly faster in the TBG-siCDK11-treated and TBG-siCK2-treated 


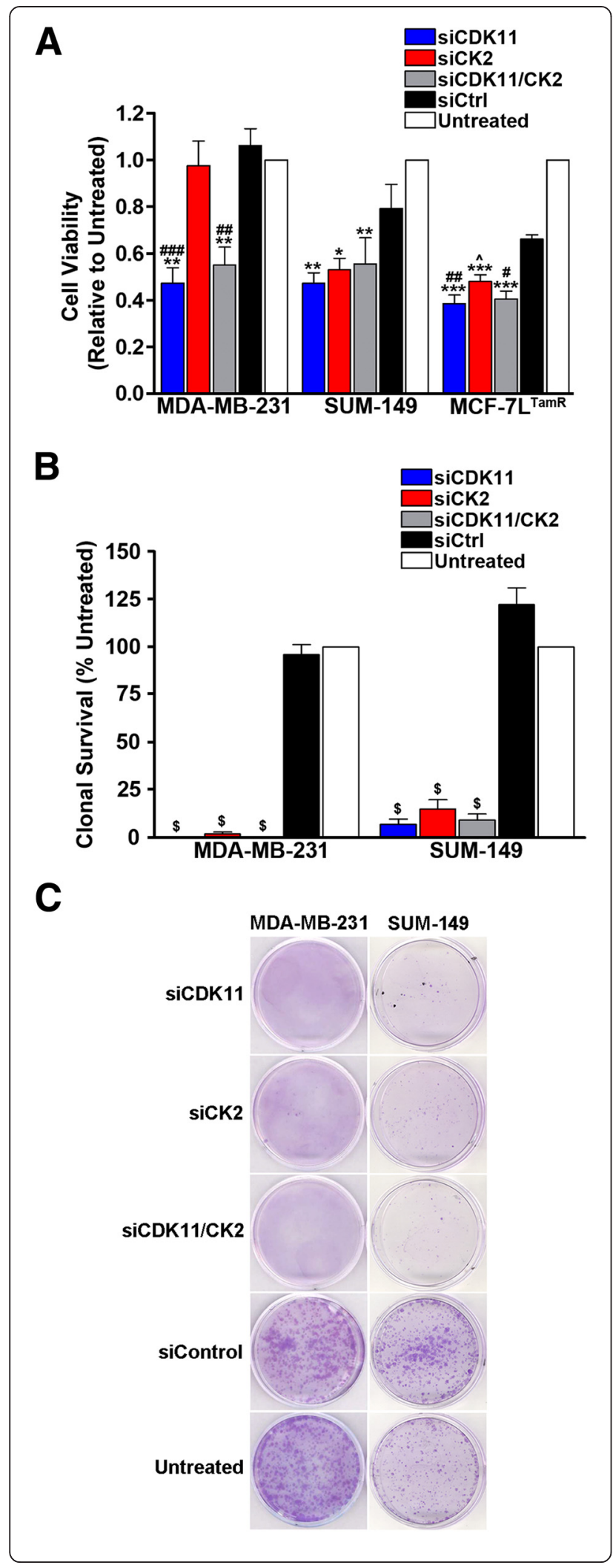

Figure 4 Small interfering RNA-mediated downregulation of CDK11 and CK2 in breast cancer cells decreases cell viability and inhibits clonal survival. (A) Breast cancer cells were transfected with $30 \mathrm{nM}$ single small interfering RNA (siRNA) or 15 nM each of the two siRNAs combined as indicated. After 96 hours, cell viability was determined relative to the untreated cells. Means \pm standard errors (SEs) are presented. ${ }^{*} P<0.05$. ${ }^{* *} P<0.01$, ${ }^{*}{ }^{*} P<0.001$ relative to untreated. ${ }^{\wedge} P=0.055,{ }^{\#} P<0.05,{ }^{\# \#} P<0.01,{ }^{\# \# \#} P<0.001$ relative to siCtrl. (B) Triple-negative breast cancer (TNBC) cells were transfected twice with $30 \mathrm{nM}$ single siRNAs or $15 \mathrm{nM}$ each of the two siRNAs combined as indicated and as described in Materials and methods. Seven days after the second transfection, cell colonies were stained and counted. Means \pm SE are presented. ${ }^{\$} P<0.0001$ relative to siCtrl and untreated. (C) Representative crystal violet stained colonies on $35 \mathrm{~mm}$ plates 7 days after the second siRNA transfection as described in (B). Cell lines are indicated above the plate images and siRNA transfections are indicated to the left of the plate images. CDK, cyclin-dependent kinase; CK2, casein kinase 2; si, small interfering.

tumors, analogous to what was seen in cultured cells. TBG-siCK2 treatment resulted in CK2 $\alpha$ protein expression reduced to $69 \%(P=0.010)$, CK $2 \alpha^{\prime}$ reduced to $74 \%$, and CK2 $\beta$ increased to $121 \%$. Unexpectedly, TBGsiCDK11-treated tumors showed reduced expression of CK $2 \alpha(P=0.008)$ and CK $2 \alpha^{\prime}$, and TBG-siCK2-treated tumors showed reduced expression of $\mathrm{CDK} 11^{\mathrm{p} 110}$ $(P=0.039)$. TBG-siCK2 treatment also increased cyclin L1 $\alpha$ expression (Figure $7 \mathrm{C}$ ). These data demonstrate reduced expression of targeted proteins, and some possible cross-influence between the two protein kinase complexes.

The tumor lysates were further examined for effects on downstream death signals. Bcl-xL protein was slightly reduced to $91 \%$ and $81 \%$ following TBG-siCDK11 and TBG-siCK2 treatments, respectively, although neither were statistically significant (Figure $7 \mathrm{C}$ ); no changes in caspase 3 protein expression were detected (data not shown). A small decrease to $86 \%$ was observed for survivin in TBG-siCDK11-treated tumors, whereas a significant decrease in survivin expression to $25 \%(P=0.001)$ was seen in TBG-siCK2-treated tumors (Figure 7C).

\section{Discussion}

This work represents the first report specifically investigating CDK11 and CK2 as targets for in vivo TNBC therapy. The significance of CDK11 as the proposed therapeutic target lies in the possibility of affecting both mitotically cycling and noncycling or quiescent malignant cells because the expression and functions of CDK11 isoforms affect both proliferating and quiescent cells. This dual consequence of targeting CDK11 adds unique functionality not observed by targeting family members such as CDK1, CDK2, CDK4, or CDK6. Thus, CDK11 downregulation would potentially overcome a known failure point in some existing cancer therapeutics, 


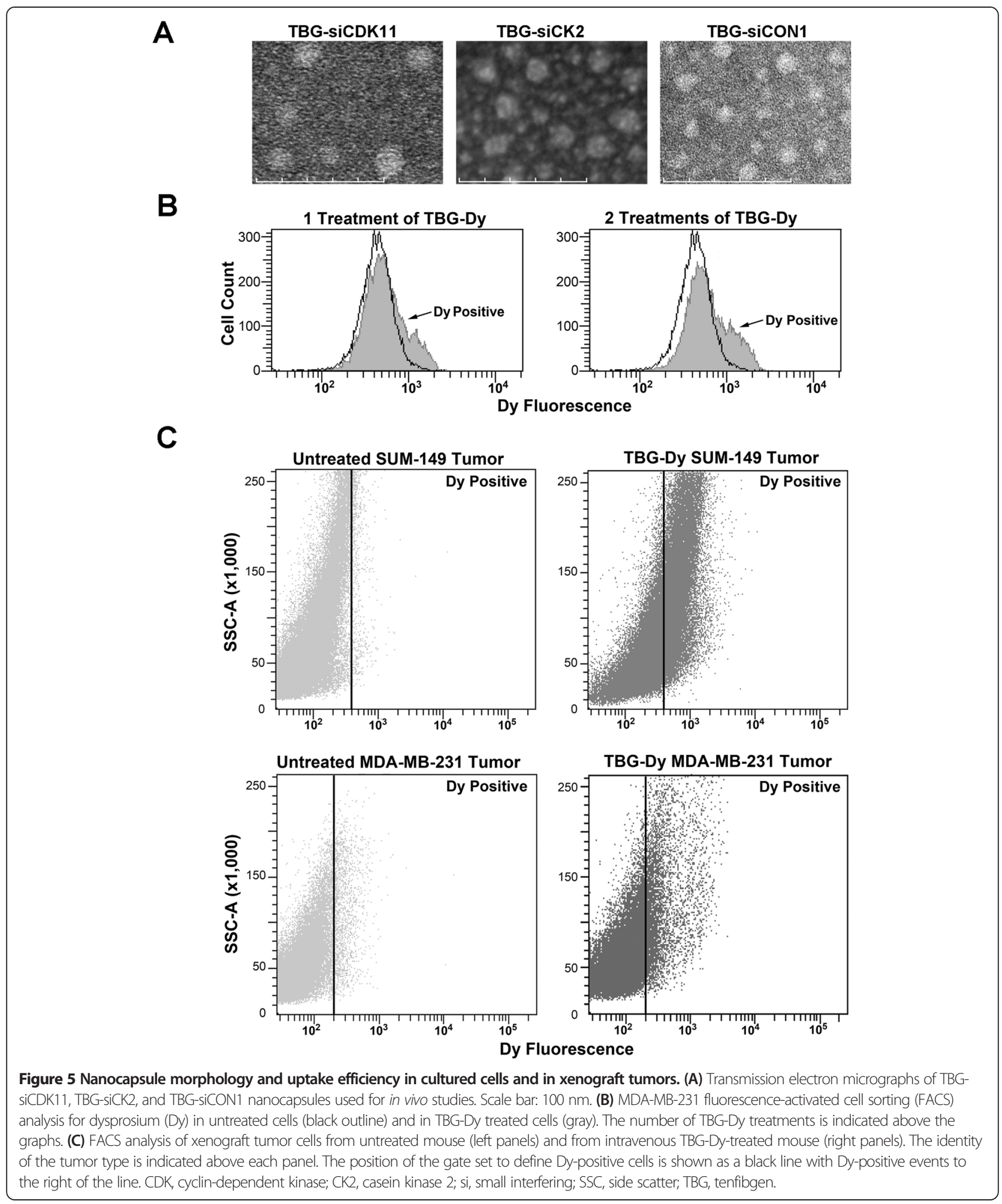

which is the lack of efficacy in quiescent cells $[66,67]$. The utility of targeting CDK11 is further supported by a recent investigation using intratumoral delivery of naked siRNAs in osteosarcoma xenograft tumors that demonstrated the efficacy of reduced CDK11 expression in this model [15].
The significance of CK2 as the proposed target is found in the extensive functions this master regulator performs in cells, and its critical involvement in the oncogenic phenotype $[37,43]$. Notably, increased expression of CK2 $\alpha$ in the mouse mammary gland under control of the MMTV-LTR 
Table 6 Nanocapsule characteristics and information

\begin{tabular}{|c|c|c|c|c|c|}
\hline Shell ligand & Particle size $(\mathrm{nm})^{\mathrm{a}}$ & Zeta potential $(\mathrm{meV})^{\mathbf{b}}$ & Morphologyc & Cargo $^{\mathrm{d}}$ & Sequence $^{\mathrm{e}}$ \\
\hline Tenfibgen & $27.7 \pm 4.6$ & $-7.4 \pm 4.2$ & Uniform, single capsules & siCDK11 & 5'-gagcgagcagcagcgugugdTdT-3' \\
\hline \multicolumn{6}{|l|}{$27 \mathrm{kDa}$} \\
\hline Tenfibgen & $20.7 \pm 5.2$ & $-1.7 \pm 2.4$ & Uniform, single capsules & siCK2 & 5'-auacaacccaaacuccacaudTdT-3' \\
\hline \multicolumn{6}{|l|}{$27 \mathrm{kDa}$} \\
\hline Tenfibgen & $16.2 \pm 2.4$ & $-7.8 \pm 4.2$ & Uniform, single capsules & siCON1 & 5'-uagcgacuaaacacaucaauudTdT-3' \\
\hline \multicolumn{6}{|l|}{$27 \mathrm{kDa}$} \\
\hline
\end{tabular}

resulted in a transgenic mouse model of breast cancer [49]. Further, a recent report highlighted the anti-survival effects of targeting CK2 in breast cancer [68], and oral treatment of mice carrying BT-474 breast cancer xenografts with the CK2 inhibitor CX-4945 inhibited xenograft tumor growth [69]. Data presented here showed that knockdown of either of these kinases using siRNA technology was effective at inducing cell death in cultured cells as well as TNBC xenograft tumors. Although we focused primarily on TNBC in this work, CK2 and CDK11 targeting strategies are likely to be effective across the breast cancer subtypes; however, further investigation will be needed to verify this supposition.

Basing the choice of therapeutic target genes on those that demonstrate increased mRNA expression levels in cancer compared with normal tissue results in omission of some candidates. mRNA levels cannot consistently be used as surrogates for the corresponding protein expression levels; in fact, less than $50 \%$ of genes demonstrate correlation between RNA and protein expression levels $[70,71]$. Moreover, there is the added complication that loss of translational control of gene expression is a

Table 7 Fluorescence-activated cell sorting analysis of TBG-Dy uptake

\begin{tabular}{lll}
\hline Cell line or tumor & Treatment & Dy-positive (\%) \\
\hline MDA-MB-231 & Untreated & 1.9 \\
MDA-MB-231 & TBG-Dy 1× & 14.4 \\
MDA-MB-231 & TBG-Dy 2× & 21.5 \\
SUM-149 & Untreated & 0.9 \\
SUM-149 & TBG-Dy & 13.1 \\
SUM-149 tumor 1 & Untreated & 1.2 \\
SUM-149 tumor 2 & i.v. TBG-Dy & 36.0 \\
SUM-149 tumor 3 & i.v. TBG-Dy & 37.1 \\
SUM-149 tumor 4 & i.v. TBG-Dy & 28.5 \\
MDA-MB-231 tumor 1 & Untreated & 1.7 \\
MDA-MB-231 tumor 2 & i.v. TBG-Dy & 11.0 \\
\hline
\end{tabular}

Dy, dysprosium; i.v., intravenous; TBG, tenfibgen. common event in solid tumors, including breast cancer [72]. Loss of translational control might account for the close correlation of CDK11 transcript and protein levels in the malignant cultured cell lines as compared with the nontransformed cells MCF-10A and MCF-12A. In normal tissue the CDK11 RNA levels are in the low range and the protein levels are in mid to high ranges, whereas in the cancer cell lines the RNA levels are in the mid range and more closely match the protein levels that are mid to high [62]. The RNAseq data we evaluated for CDK11 indicated an increase in basal breast cancer mRNA expression compared with the luminal B subtype and not compared with normal breast or other breast cancer subtypes; however, our IHC analysis of breast tissue showed an increase in CDK11 protein expression intensity in TNBC compared with normal breast. Future investigation into the post-transcriptional regulation of CDK11 in breast cancer may reveal further insights into the regulatory mechanisms in these malignancies.

In the past, although CK2 protein expression has been upregulated in all cancer types investigated to date $[43,73]$, CK2 was not typically identified as a good target gene because microarray analysis did not show a significant increase in its RNA expression. More recently, the availability of RNAseq data has provided a new store of unbiased data on transcript expression. Protein atlas data show that, in normal tissue, CK $2 \alpha$ RNA expression is low and the protein expression levels are mid to high [74]. CK $2 \alpha$ expression in cancer cell lines shows midlevel RNA expression and mid to high levels for protein, demonstrating increased concordance of RNA and protein expression in cancer. Our RNAseq analyses here demonstrated increased CK $2 \alpha$ and CK $2 \beta$ mRNA expression in TNBC compared with normal tissue, validating the utility of CK2 as a target in TNBC. While increased $\mathrm{CK} 2 \alpha$ protein expression in overall breast cancer is established, the more specific roles of $\mathrm{CK} 2 \alpha$ and CK2 $\beta$ expression at the protein level in TNBC are not yet defined $[44,75]$. 
A

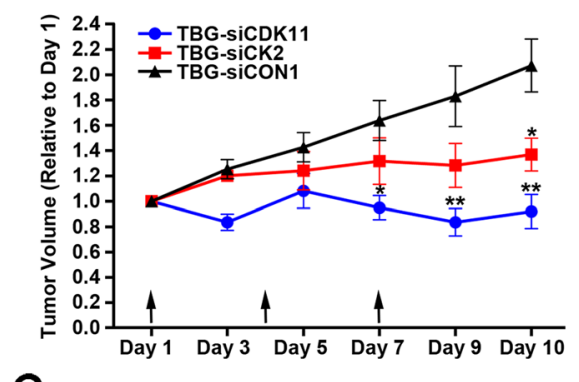

C

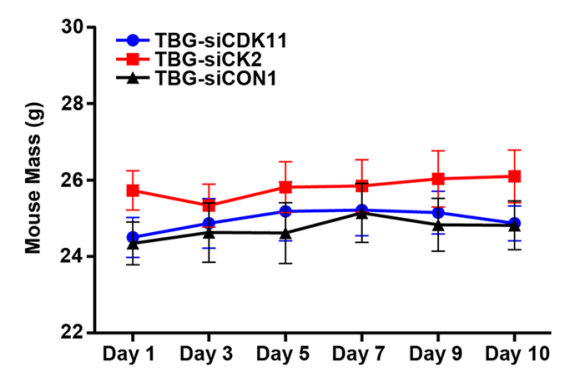

B
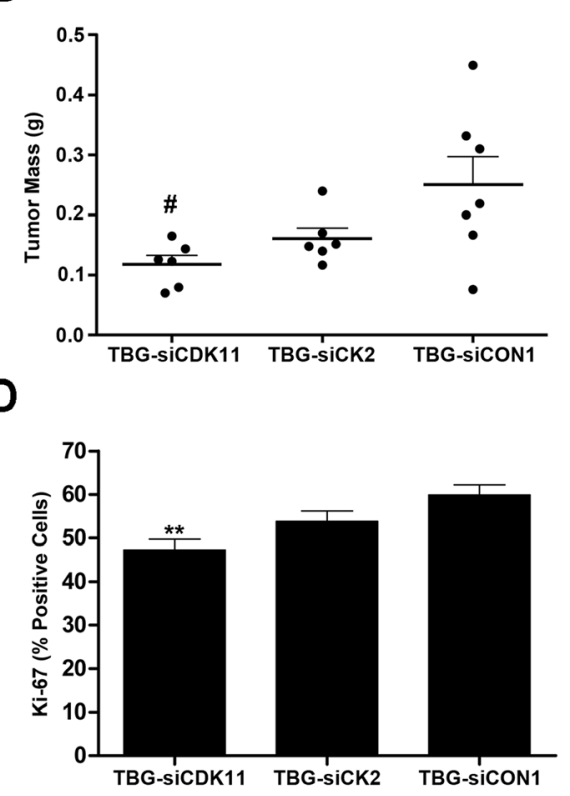

Figure 6 Therapeutic effects of TBG-siCDK11 and TBG-siCK2 treatment in MDA-MB-231 xenograft tumors. (A) Primary tumor volumes are shown following intravenous treatments at $0.01 \mathrm{mg} / \mathrm{kg}$ TBG-siCDK11, TBG-siCK2, or TBG-siCON1 on days 1, 4 and 7 (indicated by arrows). Means \pm standard errors (SEs) are presented (TBG-siCDK11 and TBG-siCK2, $n=6$; TBG-siCON1, $n=7$ ). ${ }^{*} P<0.05$, ${ }^{*} P<0.01$. (B) Primary tumor masses are shown following treatments as described in (A). Thick line, mean; thin bar, SE (TBG-siCDK11 and TBG-siCK2, $n=6$; TBG-siCON1, $n=7$ ). ${ }^{\#} P<0.05$. (C) Masses of the mice throughout the study for each treatment group. Means are presented and error bars represent the SE. (D) Percentage of Ki-67-positive cells was analyzed as described in Materials and methods and is shown graphically. Least-squares means are presented and error bars represent SE. ${ }^{*} P<0.01$. CDK, cyclin-dependent kinase; CK2, casein kinase 2; si, small interfering; TBG, tenfibgen.

Targeting CDK11 and CK2 in combination in cultured cells did not notably increase the induction of cell death over that observed targeting the kinases individually, so the combination was not tested in vivo. Additionally, no reduction in CK $2 \alpha \alpha^{\prime}$ mRNA at 24 hours or protein expression at 72 hours was observed when CDK11 was downregulated using siRNA in cultured cells, and the reverse for CDK11 expression levels in siCK2 transfected cells was also true. Interestingly, the treated tumor data here suggest some reciprocal influence between members of the CDK11 and CK2 protein complexes that was not seen in cultured cells. We observed loss of $\mathrm{CDK} 11^{\mathrm{p} 110}$ upon downregulation of CK2 $\alpha \alpha^{\prime}$, and loss of CK2 $\alpha \alpha^{\prime}$ upon downregulation of CDK11 ${ }^{\mathrm{p} 110}$. Cyclin L1 protein expression was increased following downregulation of either kinase. We have demonstrated previously that CDK11 and CK2 protein kinase complexes interact with one another within larger complexes regulating RNA transcription and splicing $[9,23,24]$. Further, we have shown that CK2 phosphorylates CDK11 ${ }^{\mathrm{p} 110}$ [24]. Thus, it is possible that downregulation of one of these survival kinases in vivo is acting to impact the expression of the other kinase, contributing to the decreased survival of the TNBC cells. CK2 regulates survivin gene expression in cultured cells such that loss of CK2 activity decreases survivin expression [76,77]. The significant downregulation of survivin protein following TBG-siCK2 treatment, but not following TBG-siCDK11 treatment, suggests that downregulation of CK2 in the TBGsiCDK11-treated tumors possibly occurred too late in the acute response study to have markedly affected survivin expression at the time of tumor collection.

Detection of CDK11 mRNA cleavage products in TBG-siCDK11-treated tumors demonstrates that the siRNA is acting through the RISC/Argonaute 2 pathway. The siCDK11 siRNA sequence used in this experiment has 3/19 mismatches comparing the human CDK11A and $C D K 11 B$ genes with the homologous mouse CDK11B (Cdc2L1) sequence; human siCDK11 is thus not likely to knockdown mouse CDK11 expression by Argonaute 2/RISC-based mechanisms, and the RACE products detected most probably derive from the human xenograft tumor cells. For TBG-siCK2-treated tumors, we were able to amplify CK2 $\alpha$ but not CK2 $\alpha^{\prime}$ mRNA cleavage products. The siCK 2 siRNA sequence has $1 / 20$ mismatches with human $\mathrm{CK} 2 \alpha^{\prime}$, and this may explain why it is more difficult to detect CK2 $2 \alpha^{\prime}$ cleavage product. We did not have enough tumor material after protein analyses to perform human-specific quantitative real-time PCR for the MDA-MB-231 treatment study; however, the specific detection of the mRNA cleavage products in both SUM-149 and MDA-MB-231 tumors 


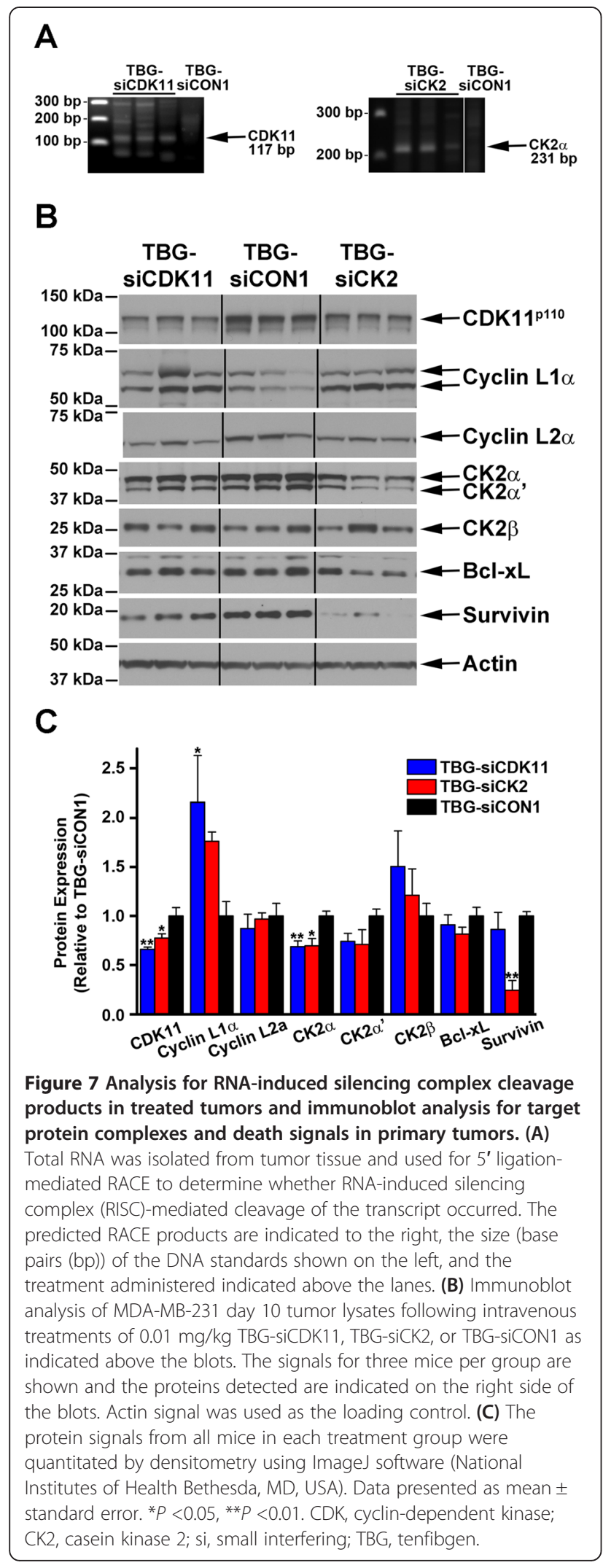

from mice treated intravenously using the TBGsiCDK11 and TBG-siCK2 nanocapsules, respectively, suggests that the appropriate transcripts are targeted for reduction. The effect of TBG-siCDK11 and TBG-siCK2 treatment on target mRNA levels will be determined in a future study.

There is ongoing research to develop small molecule inhibitors for several CDKs; however, to our knowledge no specific inhibitor of CDK11 has emerged. Many inhibitors to CK2 have been developed, and the inhibitor CX-4945 initially used in clinical trials as a single agent - is currently in clinical trials as a combinatorial agent with gemcitabine and cisplatin for treatment of cholangiocarcinoma. It is well documented that cancer cells frequently circumvent the effectiveness of small molecule inhibitors over time, thus necessitating the development of alternate strategies for cancer therapy [78,79]. Additionally, unlike small molecule inhibitors, targeting the expression of an individual protein using siRNAs provides a means to precisely impact its expression and activity, providing potential insight into novel interactions and/or pathways that are specific for that protein.

Our TBG nanocapsule containing siRNAs directed against either both CDK11 genes or against CK2 $\alpha$ and $\mathrm{CK} 2 \alpha^{\prime}$ provides protection to the nucleic acid during circulation and releases the siRNA within the cancer cells to downregulate the targeted gene expression. Malignant cell-directed treatment using the TBG nanoencapsulation technology enables targeting of survival genes without associated harm from downregulation of essential genes in normal cells [1,3]. Interestingly, reduction of less than $35 \%$ of either kinase in MDA-MB-231 tumors resulted in significant effects on tumor volume relative to controls after only three doses of the therapeutic agents. Further, treatment with TBG-siCDK11 also significantly decreased proliferative activity. These results demonstrate that moderate knockdown of either CDK11 or CK2 significantly impacts the growth and viability of TNBC tumors. Future work will focus on investigating the use of TBG-siCDK11 and TBGsiCK2 in various models of breast cancer as well as the interplay between CDK11 and CK2 and their potential co-regulation.

\section{Conclusions}

CDK11 expression and CK2 expression are individually essential for breast cancer cell survival, including TNBC in culture and in a MDA-MD-231 xenograft model. Our data demonstrate that TBG nanoencapsulation of anti-CDK11 or anti-CK2 siRNAs is a highly specific means of successfully delivering the drug to malignant cells in vivo, and moderate knockdown of either kinase resulted in significant therapeutic benefit. We propose that CDK11 and CK2 serve as promising targets for further development of treatment in breast cancer. 


\section{Abbreviations}

ANOVA: analysis of variance; CDK: cyclin-dependent kinase; CK2: casein kinase 2; DMEM: Dulbecco's modified Eagle's medium; Dy: dysprosium; EDTA: ethylenediamine tetraacetic acid; FACS: fluorescence-activated cell sorting; FBS: fetal bovine serum; IHC: immunohistochemistry; PBS: phosphatebuffered saline; RISC: RNA-induced silencing complex; RNAi: RNA interference; siCDK11: small interfering RNA to cyclin-dependent kinase 11; siCK2: small interfering RNA to CK2aa'; siCON1: small interfering RNA to control siRNA CON1; siRNA: small interfering RNA; TBG: tenfibgen (carboxyterminal fibrinogen globe domain of tenascin-C); TNBC: triple-negative breast cancer.

\section{Competing interests}

GMU has ownership interest (including patents) in GeneSegues, Inc. None of the other authors has any financial or other interest with regard to the submitted manuscript that might be construed as a conflict of interest.

\section{Authors' contributions}

BTK conceived, designed and performed experiments, analyzed and interpreted data, and edited the manuscript. GMU designed and formulated the TBG-siCDK11 nanocapsules, synthesized all nanocapsules, and discussed the experimental design. MJA designed and performed immunofluorescence and IHC experiments. RIV performed statistical analyses and critically evaluated the manuscript. CMH performed all bioinformatics analyses and critically evaluated the manuscript. KA discussed the results and edited and critically evaluated the manuscript. JHT conceived of the studies, designed and performed experiments, analyzed data, and wrote the manuscript. All authors have given final approval of the manuscript to be published and agree to be accountable for all aspects of the work in ensuring that questions related to the accuracy or integrity of any part of the work are appropriately investigated and resolved.

\section{Acknowledgements}

The authors thank Omar Cespedes-Gomez and Daniel P Shaughnessy for excellent technical assistance. Transmission electron microscopy images were acquired by Richard An (IHC World, Bethesda, MD, USA). This work is dedicated to the memory of Dr Jill M Lahti.

\section{Grant sponsors}

This work was supported by the Minnesota Veterans Medical Research and Education Foundation (JHT); Merit Review research funds (1IO1B001731) awarded by the Department of Veterans Affairs (KA); research grant CA150182 awarded by the National Cancer Institute, National Institutes of Health (NIH), Department of Health and Human Services (KA); research grants CA158730 and DK067436 awarded by National Cancer Institute and National Institute of Diabetes and Digestive and Kidney Diseases, respectively, NIH, Department of Health and Human Services (BTK); and research grants HHS-N261-2008-00027/N42CM-2008-00027C, CA99366, and CA119556 awarded by National Cancer Institute, NIH, Department of Health and Human Services (GMU).

\section{Disclaimer}

The views expressed in this article are those of the authors and do not necessarily reflect the position or policy of the US Department of Veterans Affairs or the US government.

\footnotetext{
Author details

${ }^{1}$ Research Service (151), Minneapolis VA Health Care System, One Veterans Drive, Minneapolis, MN 55417, USA. ²Department of Laboratory Medicine and Pathology, University of Minnesota, 420 Delaware Street, SE, Minneapolis, MN, USA. ${ }^{3}$ Masonic Cancer Center, University of Minnesota, 717 Delaware Street SE Room 130, Minneapolis, MN 55414, USA. ${ }^{4}$ GeneSegues Inc, 3180 High Point, Chaska, MN 55318, USA. ${ }^{5}$ Minnesota Supercomputing Institute, University of Minnesota, 117 Pleasant Street SE, Minneapolis, MN 55455, USA. ${ }^{6}$ Department of Urology, University of Minnesota, 420 Delaware St. SE, Minneapolis, MN 55455, USA.
}

Received: 15 July 2014 Accepted: 27 January 2015

Published online: 11 February 2015

\section{References}

1. Unger GM, Kren BT, Korman VL, Kimbrough TG, Vogel Rl, Ondrey FG, et al. Mechanism and efficacy of sub-50 $\mathrm{nm}$ tenfibgen nanocapsules for cancer cell-directed delivery of anti-CK2 RNAi to primary and metastatic squamous cell carcinoma. Mol Cancer Ther. 2014;13:2018-29.

2. Trembley JH, Unger GM, Korman VL, Tobolt DK, Kazimierczuk Z, Pinna LA, et al. Nanoencapsulated anti-CK2 small molecule drug or siRNA specifically targets malignant cancer but not benign cells. Cancer Lett. 2012;315:48-58.

3. Trembley JH, Unger GM, Korman VL, Abedin MJ, Nacusi LP, Vogel Rl, et al. Tenfibgen ligand nanoencapsulation delivers bi-functional anti-CK2 RNAi oligomer to key sites for prostate cancer targeting. PLoS One. 2014;9:1-12. doi: 10.1371/journal.pone.0109970.

4. Malumbres M, Harlow E, Hunt T, Hunter T, Lahti JM, Manning G, et al. Cyclin-dependent kinases: a family portrait. Nat Cell Biol. 2009;11:1275-6.

5. Lim S, Kaldis P. Cdks, cyclins and CKls: roles beyond cell cycle regulation. Development. 2013;140:3079-93.

6. Li T, Inoue A, Lahti JM, Kidd VJ. Failure to proliferate and mitotic arrest of CDK11p110/p58-null mutant mice at the blastocyst stage of embryonic cell development. Mol Cell Biol. 2004;24:3188-97.

7. Mackeigan JP, Murphy LO, Blenis J. Sensitized RNAi screen of human kinases and phosphatases identifies new regulators of apoptosis and chemoresistance. Nat Cell Biol. 2005;7:591-600

8. Trembley JH, Loyer P, Hu D, Li T, Grenet J, Lahti JM, et al. Cyclin dependent kinase 11 in RNA transcription and splicing. In: Moldave K, editor. Progress in nucleic acid research and molecular biology, vol. 77. San Diego, CA: Elsevier Academic Press; 2004. p. 263-88.

9. Loyer P, Trembley JH, Grenet JA, Busson A, Corlu A, Zhao W, et al. Characterization of cyclin L1 and L2 interactions with CDK11 and splicing factors: influence of cyclin L isoforms on splice site selection. J Biol Chem. 2008;283:7721-32.

10. Yang L, Li N, Wang C, Yu Y, Yuan L, Zhang M, et al. Cyclin L2, a novel RNA polymerase II-associated cyclin, is involved in Pre-mRNA splicing and induces apoptosis of human hepatocellular carcinoma cells. J Biol Chem. 2004;279:11639-48.

11. de Graaf K, Hekerman P, Spelten O, Herrmann A, Packman LC, Büssow K et al. Characterization of cyclin L2, a novel cyclin with an arginine/serinerich domain: phosphorylation by DYRK1A and colocalization with splicing factors. J Biol Chem. 2004;279:4612-24.

12. Dickinson LA, Edgar AJ, Ehley J, Gottesfeld JM. Cyclin L is an RS domain protein involved in pre-mRNA splicing. J Biol Chem. 2002;277:25465-73.

13. Berke JD, Sgambato V, Zhu P-P, Lavoie B, Vincent M, Krause M, et al. Dopamine and glutamate induce distinct striatal splice forms of Ania-6, an RNA polymerase II-associated cyclin. Neuron. 2001;32:277-87.

14. Cheng S-WG, Kuzyk MA, Moradian A, Ichu T-A, Chang VC-D, Tien JF, et al. Interaction of cyclin-dependent kinase 12/CrkRS with cyclin K1 is required for the phosphorylation of the C-terminal domain of RNA polymerase II. Mol Cell Biol. 2012;32:4691-704.

15. Duan Z, Zhang J, Choy E, Harmon D, Liu X, Nielsen P, et al. Systematic kinome shRNA screening identifies CDK11 (PITSLRE) kinase expression is critical for osteosarcoma cell growth and proliferation. Clin Cancer Res. 2012;18:4580-8.

16. Tiedemann RE, Zhu YX, Schmidt J, Shi CX, Sereduk C, Yin H, et al. Identification of molecular vulnerabilities in human multiple myeloma cells by RNA interference lethality screening of the druggable genome. Cancer Res. 2012;72:757-68.

17. Mitra S, Mazumder D, Basu PS, Mondal RK, Roy A, Roychoudhury S, et al. Amplification of CyclinL1 in uterine cervical carcinoma has prognostic implications. Mol Carcinog. 2010;49:935-43.

18. Redon R, Hussenet T, Bour G, Caulee K, Jost B, Muller D, et al. Amplicon mapping and transcriptional analysis pinpoint cyclin $L$ as a candidate oncogene in head and neck cancer. Cancer Res. 2002;62:6211-7.

19. Sticht C, Hofele C, Flechtenmacher C, Bosch FX, Freier K, Lichter P, et al. Amplification of cyclin L1 is associated with lymph node metastases in head and neck squamous cell carcinoma (HNSCC). Br J Cancer. 2005;92:770-4.

20. Jia B, Choy E, Cote G, Harmon D, Ye S, Kan Q, et al. Cyclin-dependent kinase 1 (CDK11) is crucial in the growth of liposarcoma cells. Cancer Lett. 2013;342:104-12

21. Xiang J, Lahti JM, Grenet J, Easton J, Kidd VJ. Molecular cloning and expression of alternatively spliced PITSLRE protein kinase isoforms. J Biol Chem. 1994:269:15786-94.

22. Loyer P, Trembley JH, Lahti JM, Kidd VJ. The RNP protein, RNPS1, associates with specific isoforms of the p34cdc2-related PITSLRE protein kinase in vivo. J Cell Sci. 1998;111:1495-506. 
23. Trembley JH, Hu D, Hsu L-C, Yeung C-Y, Slaughter C, Lahti JM, et al. PITSLRE p110 protein kinases associate with transcription complexes and affect their activity. J Biol Chem. 2002;277:2589-96.

24. Trembley JH, Hu D, Slaughter CA, Lahti JM, Kidd VJ. Casein kinase 2 interacts with cyclin-dependent kinase 11 (CDK11) in vivo and phosphorylates both the RNA polymerase II carboxyl-terminal domain and CDK11 in vitro. J Biol Chem. 2003;278:2265-70

25. Hu D, Mayeda A, Trembley JH, Lahti JM, Kidd VJ. CDK11 complexes promote pre-mRNA splicing. J Biol Chem. 2003;278:8623-9.

26. Loyer P, Busson A, Trembley JH, Hyle J, Grenet J, Zhao W, et al. The RNA binding motif protein 15B (RBM15B/OTT3) is a functional competitor of serine-arginine (SR) proteins and antagonizes the positive effect of the CDK11p110-cyclin L2alpha complex on splicing. J Biol Chem. 2011;286:147-59.

27. Choi HH, Choi HK, Jung SY, Hyle J, Kim BJ, Yoon K, et al. CHK2 kinase promotes pre-mRNA splicing via phosphorylating CDK11p110. Oncogene. 2014:33:108-15

28. Drogat J, Migeot V, Mommaerts E, Mullier C, Dieu M, van Bakel H, et al. Cdk11-cyclin I controls the assembly of the RNA polymerase II mediator complex. Cell Rep. 2012;2:1068-76.

29. Cornelis S, Bruynooghe Y, Denecker G, Van Huffel S, Tinton S, Beyaert R. Identification and characterization of a novel cell cycle-regulated internal ribosome entry site. Mol Cell. 2000;5:597-605.

30. Hu D, Valentine M, Kidd VJ, Lahti JM. CDK11p58 is required for the maintenance of sister chromatid cohesion. J Cell Sci. 2007:120:2424-34.

31. Wilker EW, van Vugt MATM, Artim SC, Huang PH, Petersen CP, Reinhardt HC, et al. 14-3-3[sgr] controls mitotic translation to facilitate cytokinesis. Nature. 2007:446:329-32.

32. Petretti C, Savoian M, Montembault E, Glover DM, Prigent C, Giet R. The PITSLRE/CDK11p58 protein kinase promotes centrosome maturation and bipolar spindle formation. EMBO Rep. 2006;7:418-24.

33. Yokoyama H, Gruss OJ, Rybina S, Caudron M, Schelder M, Wilm M, et al. Cdk11 is a RanGTP-dependent microtubule stabilization factor that regulates spindle assembly rate. J Cell Biol. 2008;180:867-75.

34. Barna M, Pusic A, Zollo O, Costa M, Kondrashov N, Rego E, et al. Suppression of Myc oncogenic activity by ribosomal protein haploinsufficiency. Nature. 2008;456:971-5.

35. Franck N, Montembault E, Romé P, Pascal A, Cremet J-Y, Giet R. CDK $11^{\mathrm{p} 58}$ is required for centriole duplication and Plk4 recruitment to mitotic centrosomes. PLoS One. 2011;6:e14600.

36. Meggio F, Pinna LA. One-thousand-and-one substrates of protein kinase CK2? FASEB J. 2003;17:349-68.

37. Trembley JH, Wang G, Unger G, Slaton J, Ahmed K. Protein kinase CK2 in health and disease: CK2: a key player in cancer biology. Cell Mol Life Sci. 2009:66:1858-67.

38. Niefind K, Issinger OG. Conformational plasticity of the catalytic subunit of protein kinase CK2 and its consequences for regulation and drug design. Biochim Biophys Acta. 1804;2010:484-92.

39. le Nguyen XT, Mitchell BS. Akt activation enhances ribosomal RNA synthesis through casein kinase II and TIF-IA. Proc Natl Acad Sci U S A. 2013:110:20681-6.

40. Tarrant MK, Rho HS, Xie Z, Jiang YL, Gross C, Culhane JC, et al. Regulation of CK2 by phosphorylation and O-GlcNAcylation revealed by semisynthesis. Nat Chem Biol. 2012;8:262-9.

41. Guerra B, Issinger OG. Protein kinase CK2 and its role in cellular proliferation, development and pathology. Electrophoresis. 1999;20:391-408.

42. Tawfic S, Yu S, Wang H, Faust R, Davis A, Ahmed K. Protein kinase CK2 signal in neoplasia. Histol Histopathol. 2001;16:573-82.

43. Ruzzene M, Pinna LA. Addiction to protein kinase CK2: a common denominator of diverse cancer cells? Biochim Biophys Acta. 1804;2010:499-504

44. Giusiano S, Cochet C, Filhol O, Duchemin-Pelletier E, Secq V, Bonnier P, et al. Protein kinase CK2alpha subunit over-expression correlates with metastatic risk in breast carcinomas: quantitative immunohistochemistry in tissue microarrays. Eur J Cancer. 2011;47:792-801.

45. Faust RA, Gapany M, Tristani P, Davis A, Adams GL, Ahmed K. Elevated protein kinase CK2 activity in chromatin of head and neck tumors: association with malignant transformation. Cancer Lett. 1996;101:31-5.

46. Faust RA, Niehans G, Gapany M, Hoistad D, Knapp D, Cherwitz D, et al. Subcellular immunolocalization of protein kinase CK2 in normal and carcinoma cells. Int J Biochem Cell Biol. 1999:31:941-9.
47. Gapany M, Faust RA, Tawfic S, Davis A, Adams GL, Ahmed K. Association of elevated protein kinase CK2 activity with aggressive behavior of squamous cell carcinoma of the head and neck. Mol Med. 1995;1:659-66.

48. Laramas M, Pasquier D, Filhol O, Ringeisen F, Descotes JL, Cochet C. Nuclear localization of protein kinase CK2 catalytic subunit (CK2a) is associated with poor prognostic factors in human prostate cancer. Eur J Cancer. 2007:43:928-34.

49. Landesman-Bollag E, Romieu-Mourez R, Song DH, Sonenshein GE, Cardiff $\mathrm{RD}$, Seldin DC. Protein kinase CK2 in mammary gland tumorigenesis. Oncogene. 2001;20:3247-57.

50. Landesman-Bollag E, Song DH, Romieu-Mourez R, Sussman DJ, Cardiff RD, Sonenshein GE, et al. Protein kinase CK2: signaling and tumorigenesis in the mammary gland. Mol Cell Biochem. 2001;227:153-65.

51. Ahmed K, Gerber DA, Cochet C. Joining the cell survival squad: an emerging role for protein kinase CK2. Trends Cell Biol. 2002;12:226-30.

52. Unger G, Trembley J, Kren B, Ahmed K. Nanoparticles in cancer therapy. In: Schwab M, editor. Encyclopedia of cancer: Springer Reference (www. springerreference.com). 31 Jan 2012 edition. Berlin: Springer-Verlag; 2009. p. 1-4.

53. Brown MS, Diallo OT, Hu M, Ehsanian R, Yang X, Arun P, et al. CK2 Modulation of NF-KB, TP53, and the malignant phenotype in head and neck cancer by anti-CK2 oligonucleotides in vitro or in vivo via sub-50-nm nanocapsules. Clin Cancer Res. 2010;16:2295-307.

54. Guttery D, Shaw J, Lloyd K, Pringle J, Walker R. Expression of tenascin-C and its isoforms in the breast. Cancer Metas Rev. 2010;29:559-606.

55. Oskarsson T, Acharyya S, Zhang XH, Vanharanta S, Tavazoie SF, Morris PG, et al. Breast cancer cells produce tenascin $C$ as a metastatic niche component to colonize the lungs. Nat Med. 2011;17:867-74.

56. Unger GM, Davis AT, Slaton JW, Ahmed K. Protein kinase CK2 as regulator of cell survival: implications for cancer therapy. Curr Cancer Drug Targets. 2004:4:77-84.

57. Bartlett DW, Davis ME. Impact of tumor-specific targeting and dosing schedule on tumor growth inhibition after intravenous administration of siRNAcontaining nanoparticles. Biotechnol Bioeng. 2008;99:975-85.

58. Tuominen VJ, Ruotoistenmaki S, Viitanen A, Jumppanen M, Isola J. ImmunoRatio: a publicly available web application for quantitative image analysis of estrogen receptor (ER), progesterone receptor (PR), and Ki-67. Breast Cancer Res. 2010;12:R56.

59. Trembley JH, Unger GM, Tobolt DK, Korman VL, Wang G, Ahmad KA, et al. Systemic administration of antisense oligonucleotides simultaneously targeting CK2alpha and alpha' subunits reduces orthotopic xenograft prostate tumors in mice. Mol Cell Biochem. 2011;356:21-35.

60. Aukhil I, Joshi P, Yan Y, Erickson HP. Cell- and heparin-binding domains of the hexabrachion arm identified by tenascin expression proteins. J Bio Chem. 1993:268:2542-53.

61. Kren BT, Unger GM, Sjeklocha L, Trossen AA, Korman V, Diethelm-Okita BM, et al. Nanocapsule-delivered Sleeping Beauty mediates therapeutic factor VIII expression in liver sinusoidal endothelial cells of hemophilia A mice. J Clin Invest. 2009;119:2086-99.

62. Human Protein Atlas Data Portal:CDK11A/HPA025061. http://www proteinatlas.org/ENSG00000008128. Accessed July 14, 2014.

63. Uhlen M, Oksvold P, Fagerberg L, Lundberg E, Jonasson K, Forsberg M, et al. Towards a knowledge-based Human Protein Atlas. Nature Biotech. 2010;28:1248-50

64. Feliciano A, Castellvi J, Artero-Castro A, Leal JA, Romagosa C, HernandezLosa J, et al. miR-125b acts as a tumor suppressor in breast tumorigenesis via its novel direct targets ENPEP, CK2-alpha, CCNJ, and MEGF9. PLoS One. 2013;8:e76247.

65. Rhodes DR, Yu J, Shanker K, Deshpande N, Varambally R, Ghosh D, et al. ONCOMINE: a cancer microarray database and integrated data-mining platform. Neoplasia. 2004;6:1-6.

66. Clevers $H$. The cancer stem cell: premises, promises and challenges. Nat Med. 2011;17:313-9.

67. Sosa MS, Bragado P, Aguirre-Ghiso JA. Mechanisms of disseminated cancer cell dormancy: an awakening field. Nat Rev Cancer. 2014;14:611-22.

68. Gray GK, McFarland BC, Rowse AL, Gibson SA, Benveniste EN. Therapeutic CK2 inhibition attenuates diverse prosurvival signaling cascades and decreases cell viability in human breast cancer cells. Oncotarget. 2014;5:6484-96.

69. Siddiqui-Jain A, Drygin D, Streiner N, Chua P, Pierre F, O'Brien SE, et al CX-4945, an orally bioavailable selective inhibitor of protein kinase CK2, inhibits prosurvival and angiogenic signaling and exhibits antitumor efficacy. Cancer Res. 2010;70:10288-98. 
70. Schwanhausser B, Busse D, Li N, Dittmar G, Schuchhardt J, Wolf J, et al. Global quantification of mammalian gene expression control. Nature. 2011;473:337-42.

71. Wilhelm M, Schlegl J, Hahne H, Gholami AM, Lieberenz M, Savitski MM, et al. Mass-spectrometry-based draft of the human proteome. Nature. 2014:509:582-7.

72. Thumma SC, Kratzke RA. Translational control: a target for cancer therapy. Cancer Lett. 2007:258:1-8.

73. Trembley JH, Chen Z, Unger G, Slaton J, Kren BT, Van Waes C, et al. Emergence of protein kinase CK2 as a key target in cancer therapy. Biofactors. 2010;36:187-95.

74. Human Protein Atlas Data Portal: CK2alpha/CAB020680. http://www. proteinatlas.org/ENSG00000101266-CSNK2A1. Accessed December 1, 2014

75. Deshiere A, Duchemin-Pelletier E, Spreux E, Ciais D, Combes F, Vandenbrouck $Y$, et al. Unbalanced expression of CK2 kinase subunits is sufficient to drive epithelial-to-mesenchymal transition by Snail1 induction. Oncogene. 2013;32:1373-83.

76. Wang G, Ahmad KA, Harris NH, Ahmed K. Impact of protein kinase CK2 on inhibitor of apoptosis proteins in prostate cancer cells. Mol Cell Biochem. 2008;316:91-7.

77. Tapia JC, Torres VA, Rodriguez DA, Leyton L, Quest AF. Casein kinase 2 (CK2) increases survivin expression via enhanced beta-catenin-T cell factor/lymphoid enhancer binding factor-dependent transcription. Proc Natl Acad Sci U S A. 2006:103:15079-84

78. Rebucci M, Michiels C. Molecular aspects of cancer cell resistance to chemotherapy. Biochem Pharmacol. 2013;85:1219-26.

79. Stegmeier F, Warmuth M, Sellers WR, Dorsch M. Targeted cancer therapies in the twenty-first century: lessons from Imatinib. Clin Pharmacol Ther. 2010;87:543-52.

\section{Submit your next manuscript to BioMed Central and take full advantage of:}

- Convenient online submission

- Thorough peer review

- No space constraints or color figure charges

- Immediate publication on acceptance

- Inclusion in PubMed, CAS, Scopus and Google Scholar

- Research which is freely available for redistribution 